\title{
UK Renal Registry 20th Annual Report: Chapter 1 UK Renal Replacement Therapy Adult Incidence in 2016: National and Centre-specific Analyses
}

\author{
Barnaby Hole ${ }^{a b}$, Julie Gilg ${ }^{a}$, Anna Casula ${ }^{a}$, Shona Methven ${ }^{c}$, Clare Castledine $^{\mathrm{d}}$ \\ ${ }^{\mathrm{a}}$ UK Renal Registry, Bristol, UK; ${ }^{\mathrm{b}}$ The University of Bristol, Bristol, UK; ${ }^{\mathrm{C}}$ Aberdeen Royal Infirmary, Foresterhill, Aberdeen, UK; \\ ${ }^{\mathrm{d}}$ Brighton and Sussex Medical School, Brighton, UK
}

\section{Keywords}

Incidence rates - Comorbidity - Diabetes - Dialysis - End stage renal disease . End stage renal failure - Established renal failure - Glomerulonephritis - Haemodialysis - Incidence • Peritoneal dialysis - Registries - Renal replacement therapy . Transplantation - Treatment modality · Acute haemodialysis

\section{Summary}

- The incidence rate in the UK decreased from 120 per million population ( $\mathrm{pmp}$ ) in 2015 to $118 \mathrm{pmp}$ in 2016 reflecting renal replacement therapy (RRT) initiation for 7,759 new patients.

- The median age of all incident patients was 64.3 years, but this was highly dependent on ethnicity (66.2 years for White incident patients, 58.7 years for non-White patients).

- Diabetic renal disease remained the single most common cause of renal failure treated by RRT (28.6\%).

- By 90 days, $66.6 \%$ of patients were on haemodialysis (HD), $19.6 \%$ on peritoneal dialysis (PD), 9.3\% had a functioning transplant (Tx) and $4.6 \%$ had died or stopped treatment.

- The percentage of RRT patients at 90 days who had a functioning transplant varied between centres from $0 \%$ to $31 \%$ (between $2 \%$ and $31 \%$ for transplanting centres and between $0 \%$ and $19 \%$ for non-transplanting centres).

- The mean eGFR at the start of RRT was $7.4 \mathrm{ml} / \mathrm{min} /$ $1.73 \mathrm{~m}^{2}$ by the CKD-EPI method and $8.5 \mathrm{ml} / \mathrm{min} /$ $1.73 \mathrm{~m}^{2}$ by the MDRD method, similar to the previous five years.

- Late presentation continued to fall from $23.9 \%$ in 2006 to $15.6 \%$ in 2016.

- Timeline codes indicated that 6,891 first-ever HD sessions were delivered in 2016 across 62 centres in England, Wales and Northern Ireland. Of these, $2,581(37.5 \%)$ were classified as acute $\mathrm{HD}$ and the remaining $4,310(62.5 \%)$ as $\mathrm{HD}$ for established renal failure (ERF). Data relating to the first HD session were available for 5,373 (78.0\%) HD starts.

- After centre exclusions, 4,191 (79.7\%) of 5,257 timeline and sessional HD start dates were on the same day and $97.2 \%$ were within two weeks of each other. These low levels of discordance are unlikely to meaningfully influence overall survival data for HD recipients.

- Of the 2,581 individuals who received acute HD, 790 (30.6\%) developed ERF and 1,791 (69.4\%) died, stopped RRT or recovered renal function.

\begin{tabular}{ll}
\hline KARGER & $\begin{array}{l}\text { C } 2018 \text { The UK Renal Registry } \\
\text { Published by S. Karger AG, Basel Karger }\end{array}$ \\
Fax +4161306 1234 & Pen cess \\
E-Mail karger@karger.com & $\begin{array}{l}\text { This article is licensed under the Creative Commons Attribution- } \\
\text { www.karger.com/nef }\end{array}$ \\
$\begin{array}{l}\text { NonCommercial-NoDerivatives 4.0 International License (CC BY- } \\
\text { NC-ND) (http://www.karger.com/Services/OpenAccessLicense). } \\
\text { Usage and distribution for commercial purposes as well as any } \\
\text { distribution of modified material requires written permission. }\end{array}$
\end{tabular}

Barnaby Hole

UK Renal Registry, Southmead Hospital, Southmead Road,

Bristol, BS10 5NB, UK

Email: renalregistry@renalregistry.nhs.uk 
- It is vital that coding is consistent between centres. The UK Renal Registry (UKRR) asks clinicians to use the timeline to record the date of first dialysis and separately, the date on which the patient is deemed to have reached ERF. This allows patients who have an acute start to be distinguished from those whose start on RRT was planned.

\section{Introduction}

This chapter contains analyses of UK adults who started renal replacement therapy (RRT) in 2016. The methodology and results for these analyses are in four sections: geographical variations in incidence rates; the demographic and clinical characteristics of patients starting RRT; analyses of late presentation and delayed referral; and analyses of acute haemodialysis sessions. The data were analysed using SAS 9.3.

\section{Definitions}

The first three sections of this chapter consider individuals who received RRT as a treatment for established renal failure (ERF). These individuals are considered 'incident to RRT' throughout this report. The term ERF is used synonymously with the terms end stage renal failure/disease (ESRF/ESRD). Since the 19th Annual Report, data have also been published for individuals who received acute haemodialysis (HD), as coded by their reporting centre. Previously, such individuals were only reported if their dialysis was subsequently recoded as being for ERF, when they failed to recover native renal function. Recoding is automatically applied at 90 days for individuals still on RRT, but can also be applied at any point between days 0 and 90 by the reporting centre. Individuals who commenced HD for acute kidney injury (AKI) and subsequently recovered renal function, or died within the first 90 days of treatment without receiving an ERF code are reported in the fourth section of this chapter. These individuals do not feature elsewhere in the UKRR report. Figure 1.1 illustrates the terms used to categorise dialysis as being acute or for ERF. See appendix B: Definitions and Analysis Criteria (www.renalreg.org) for further details. Note that individuals with a failed renal transplant who returned to dialysis are not included.

NHS England now mandates the collection of data regarding acute HD sessions. These data will help to provide a more complete picture of dialysis use in the
UK than has ever before been possible. Sessional HD data carry no information about whether the dialysis was for AKI or ERF. Distinguishing between these two indications depends entirely upon the accuracy of timeline data provided by centres.

Differences in incidence data may be seen in the 2011 to 2015 numbers now quoted when compared with previous publications because of retrospective updating of data in collaboration with renal centres. In addition, patients with acute kidney injury requiring dialysis may be coded in the subsequent year as having developed ERF, allowing the UKRR to backdate the start date of RRT.

Where applicable, pre-emptive transplant patients were allocated to their work-up centre, rather than their transplant centre. This was not possible for all patients as some centres did not supply the 'transfer out for pre-emptive transplant' timeline codes. Consequently, some patients remain allocated to their transplanting centre.

\section{UK Renal Registry coverage}

The UKRR received individual patient level data from 70 adult renal centres in the UK (five in Wales, five in Northern Ireland, nine in Scotland, 51 in England).

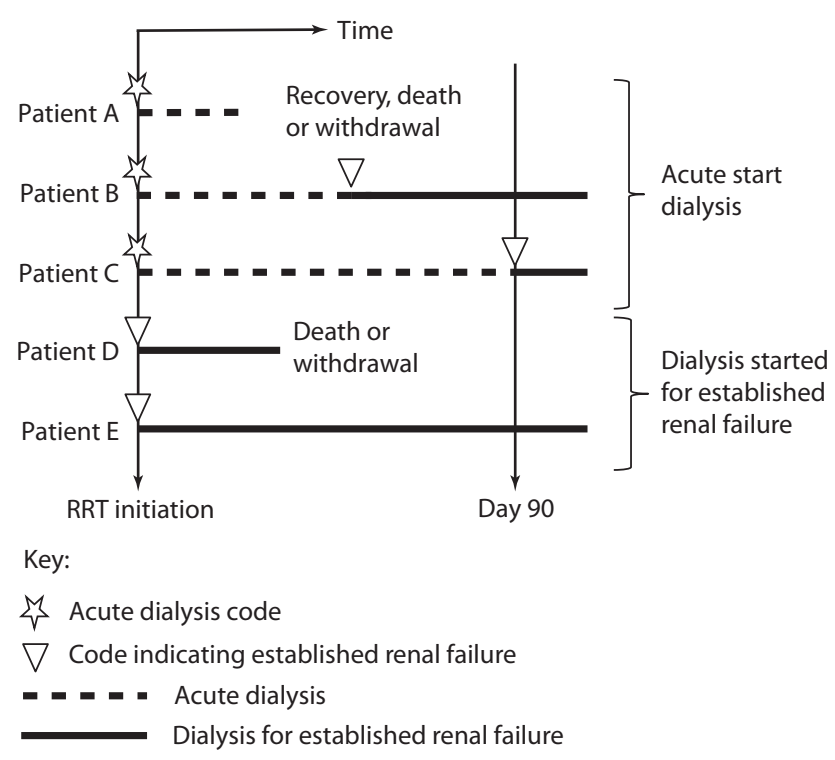

Fig. 1.1. Example histories for patients starting RRT, illustrating the use of timeline codes to define dialysis as being 'acute' or for established renal failure

Patients that follow patterns B-E receive RRT for ERF and are counted as 'incident to RRT' throughout this report. Patients that follow pattern A are not counted as 'incident to RRT' and feature only in section four of this chapter 
Cambridge renal centre (Addenbrooke's) was unable to submit 2015 or 2016 data at patient level prior to the UKRR closing the database and only provided summary numbers of patients starting RRT by treatment modality. This centre is therefore excluded from most analyses in this chapter. Data from centres in Scotland were obtained from the Scottish Renal Registry. Data on children and young adults can be found in chapter 4: Demography of the UK Paediatric Renal Replacement Therapy Population in 2016.

\section{Renal Association Guidelines}

Table 1.1 lists the relevant items from the Renal Association Guidelines on the Planning, Initiating and Withdrawal of Renal Replacement Therapy [1]. Many of the audit measures are not currently reported by the UKRR; mainly due to a high proportion of incomplete data or because the relevant data are not included in the UKRR dataset. The UKRR is working with the renal community to improve reporting across all of these measures.

Table 1.1. Summary of Renal Association (RA) audit measures relevant to RRT incidence

RA audit measure

Percentage of patients commencing RRT referred $<3$ months and $<12$ months before date of starting RRT

Percentage of incident RRT patients followed up for

$>3$ months in dedicated pre-dialysis or low clearance clinic

Proportion of incident patients on UK transplant waiting list at RRT initiation

Proportion of incident RRT patients transplanted preemptively from living donors and cadaveric donors

Mean eGFR at time of pre-emptive transplantation

Proportion of incident patients commencing peritoneal or home haemodialysis

Proportion of patients who have undergone a formal education programme prior to initiation of RRT

Proportion of haemodialysis patients who report that they have been offered a choice of RRT modality

Proportion of patients who have initiated dialysis in an unplanned fashion who have undergone formal education by 3 months

Evidence of formal continuing education programme for patients on dialysis

Proportion of incident patients known to nephrology services for 3 months or more prior to initiation (planned initiation)

Proportion of planned initiations with established access or pre-emptive transplantation

Inpatient/outpatient status of planned initiations

Mean eGFR at start of renal replacement therapy
Reported

Yes

No

Yes

Yes

No

Partly

No

No Not in UKRR dataset

No Not in UKRR dataset

No Not in UKRR dataset

Yes

Yes See appendix $\mathrm{F}$ for proportion of incident patients having pre-emptive transplantation, and see chapter 10 for dialysis access

No Not in UKRR dataset

Partly Reported but not at centre level due to poor data completeness 


\section{Geographical variation in incidence rates}

\section{Introduction}

Incidence rates vary widely between renal centres. Equity of access to RRT is hard to assess, many variables (including medical, social and demographic factors) influence rates of ERF. Thus, comparisons of crude incidence rates by geographical area are misleading. To enhance comparisons, age and sex standardised rates for each clinical commissioning group/health board (CCG/HBs) are presented along with crude rates. Population ethnicity rates are presented but adjustment for ethnicity or comorbidity was not made due to incomplete data.

\section{Methods}

See appendix D: Methodology used for Analyses and appendix E: Methodology for Estimating Catchment Populations (www.renalreg.org) for a detailed description of methods used to calculate crude and age/sex standardised incidence ratios and to estimate catchment populations.

Only one centre (Cambridge) was unable to provide patientlevel data. Aggregrated data enabled estimation of incident numbers for 2015 and 2016. These estimates are presented in tables 1.2 and 1.4, but do not feature elsewhere in this chapter. The 2011 to 2014 data were used to decide which CCG/HBs should be excluded from the calculation of age and sex standardised rates due to missing patient-level data. Those CCG/HBs where greater than $15 \%$ of the incident RRT population from 2011 to 2014 were incident patients of the Cambridge renal centre were not included in the analysis for 2015 or 2016. These CCG/ HBs are included for 2011-2014. CCG/HBs where less than 15\% of the 2011-2014 data were from Cambridge were included in the analyses, and where the percentage was between $5 \%$ and $15 \%$ are flagged in table 1.3 as their results are likely to be underestimated.

\section{Results}

Overall

In 2016, the number of adult patients starting RRT in the UK was 7,759 equating to an incidence rate of $118 \mathrm{pmp}$ (table 1.2), compared with $120 \mathrm{pmp}$ in 2015. Scotland's rate was notably lower than the rest of the UK (figure 1.2). There continued to be very marked sex differences in incidence rates which were $151 \mathrm{pmp}$ (95\% CI 147-155) in males and 86 pmp (95\% CI $83-$ 90) in females.

The denominators used for these rates were the entire population i.e. they include under 18 -year olds. When incident patients aged under 18 were included in the numerator the UK rate was $120 \mathrm{pmp}$.

Incidence rates at CCG/HB level

Table 1.3 shows incidence rates and standardised incidence ratios for CCG/HBs. There were wide variations

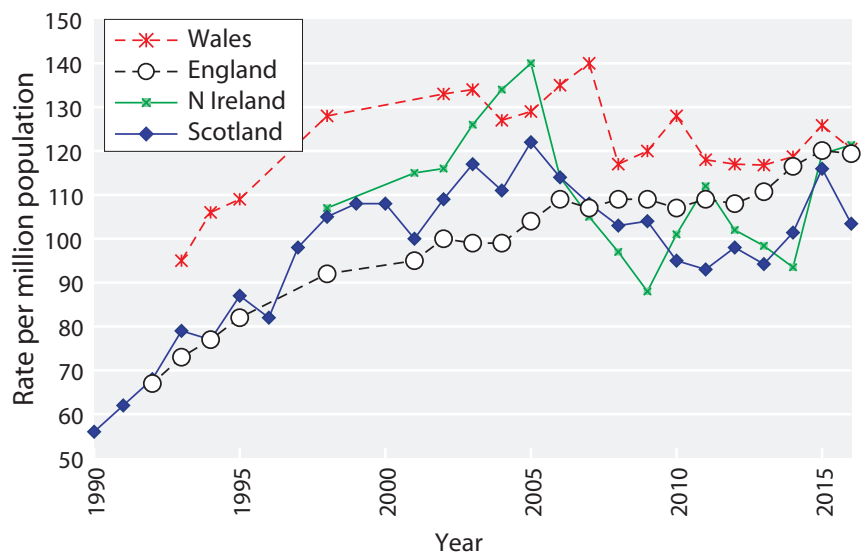

Fig. 1.2. RRT incidence rates in the countries of the UK 19902016

Table 1.2. Number of new adult patients starting RRT in the UK in 2016

\begin{tabular}{|c|c|c|c|c|c|}
\hline & England $^{\mathrm{b}}$ & $\mathrm{N}$ Ireland & Scotland ${ }^{\mathrm{c}}$ & Wales & $\mathbf{U K}^{\mathrm{b}}$ \\
\hline Number starting RRT & 6,599 & 226 & 559 & 375 & 7,759 \\
\hline Total estimated population mid-2016 (millions) ${ }^{\mathrm{a}}$ & 55.3 & 1.9 & 5.4 & 3.1 & 65.6 \\
\hline Incidence rate (pmp) & 119 & 121 & 103 & 120 & 118 \\
\hline$(95 \% \mathrm{CI})$ & $(117-122)$ & $(106-137)$ & $(95-112)$ & $(108-133)$ & $(116-121)$ \\
\hline
\end{tabular}

${ }^{a}$ Data from the Office for National Statistics, National Records of Scotland and the Northern Ireland Statistics and Research Agency - based on the 2011 census

${ }^{\mathrm{b}}$ Cambridge was unable to submit patient level data for 2015 or 2016 but provided the UKRR with information allowing their incident numbers for 2015 and 2016 to be estimated. These numbers have been used here and in table 1.4 but not elsewhere in this chapter

${ }^{c}$ The number starting RRT, and hence the RRT incidence rate, published in the Scottish Renal Registry report for the same period is slightly higher at 573 (106 pmp). This is explained by their inclusion of under 18 year olds and other differences in the definition of incident RRT patients between the two registries 
Table 1.3. Crude adult incidence rates (pmp) and age/sex standardised incidence ratios 2011-2016

CCG/HB - CCG in England, Health and Social Care Areas in Northern Ireland, Local Health Boards in Wales and Health Boards in Scotland $\mathrm{O} / \mathrm{E}$ - standardised incidence ratio

LCL - lower 95\% confidence limit

UCL - upper 95\% confidence limit

pmp - per million population

Areas with notably low incidence ratios over six years are italicised in lighter greyed areas, those with notably high incidence ratios over six years are bold in darker greyed areas - for the full methodology see appendix D

Confidence intervals are not given for the crude rates per million population but figures D1 and D2 in appendix D can be used to determine if a CCG/HB falls within the $95 \%$ confidence interval around the national average rate

Mid-2016 population data from the Office for National Statistics, National Records of Scotland and the Northern Ireland Statistics and Research Agency - based on the 2011 census

$\%$ non-White - percentage of the CCG/HB population that is non-White, from 2011 census

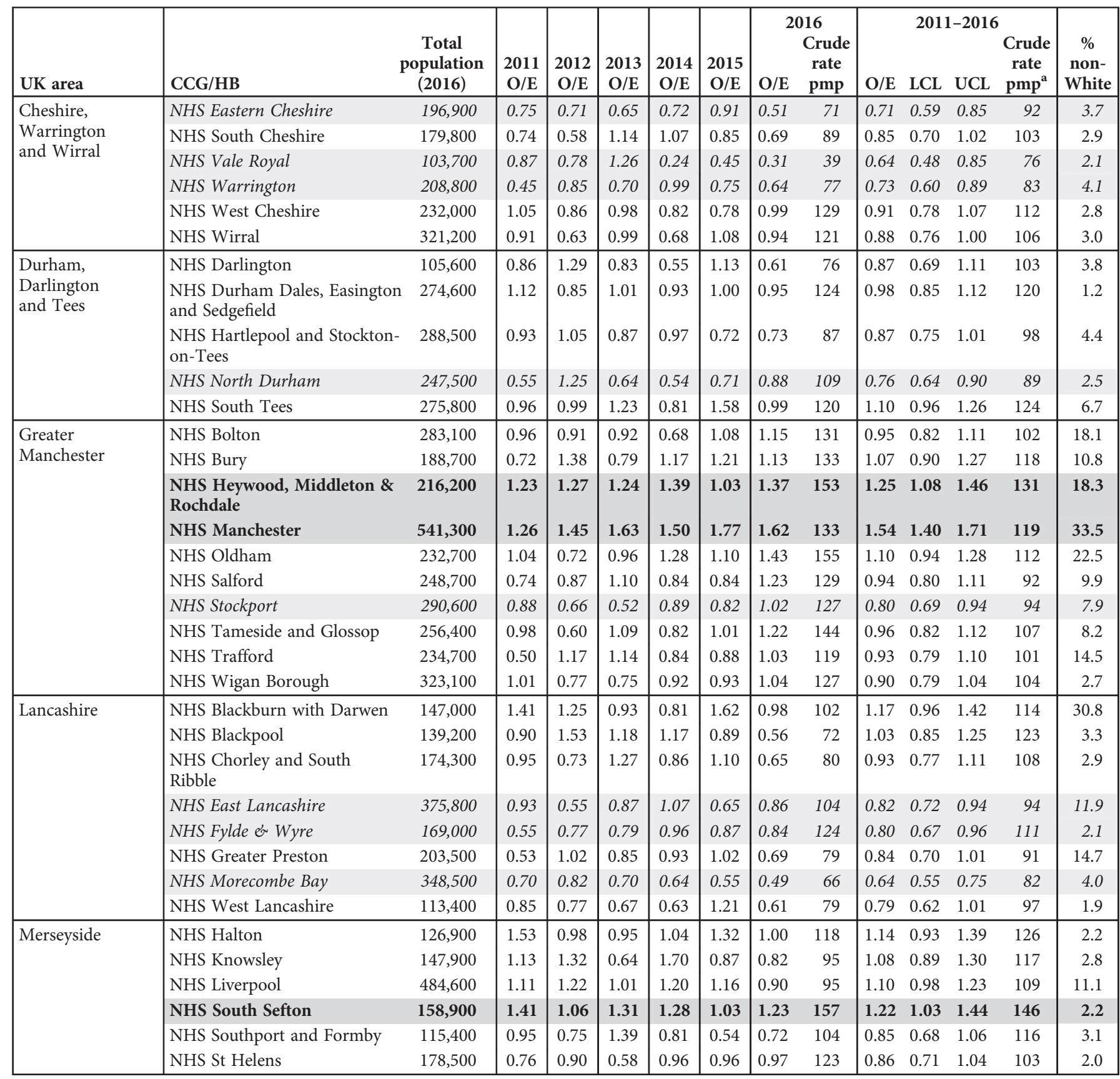


Table 1.3. Continued

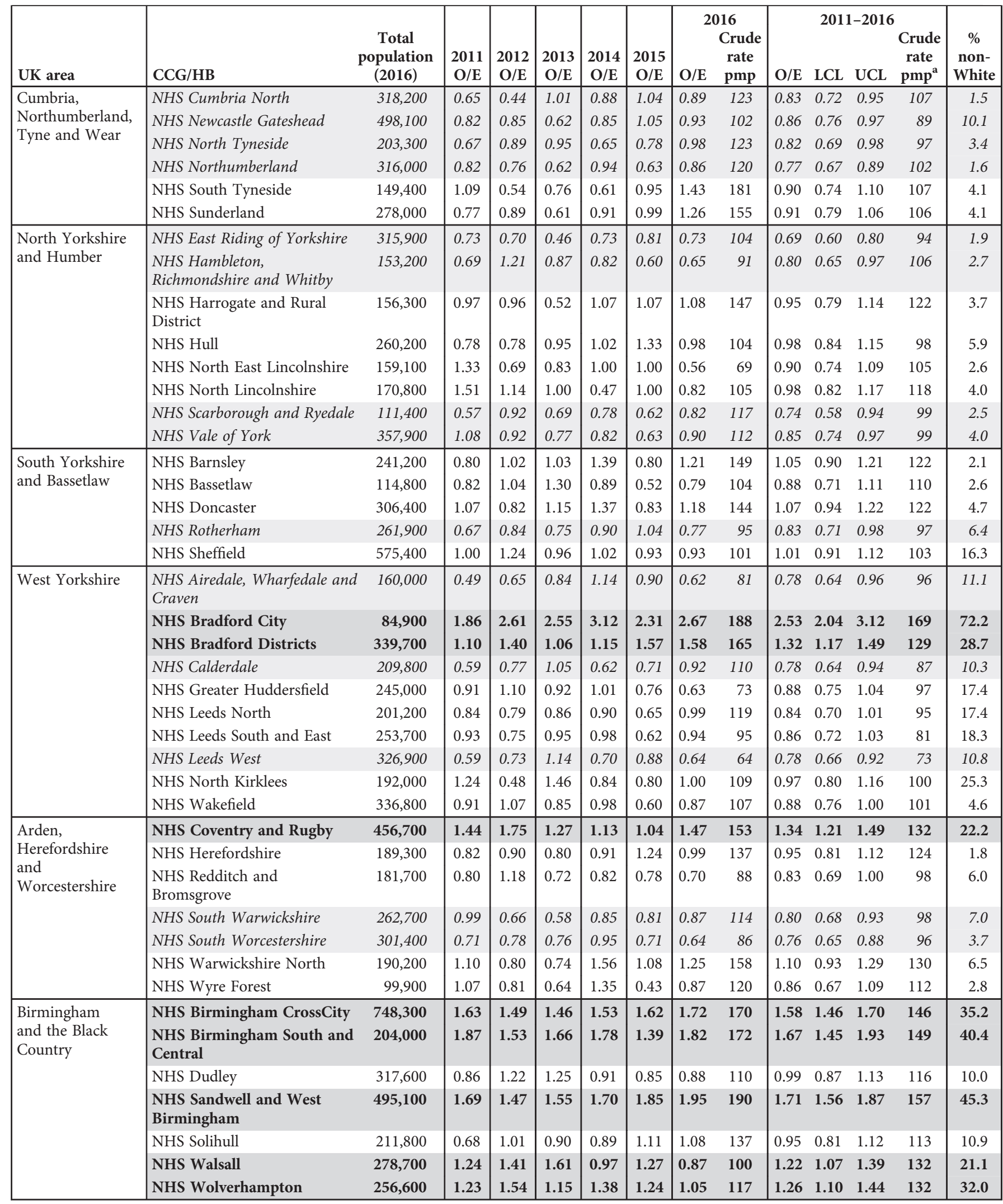


Table 1.3. Continued

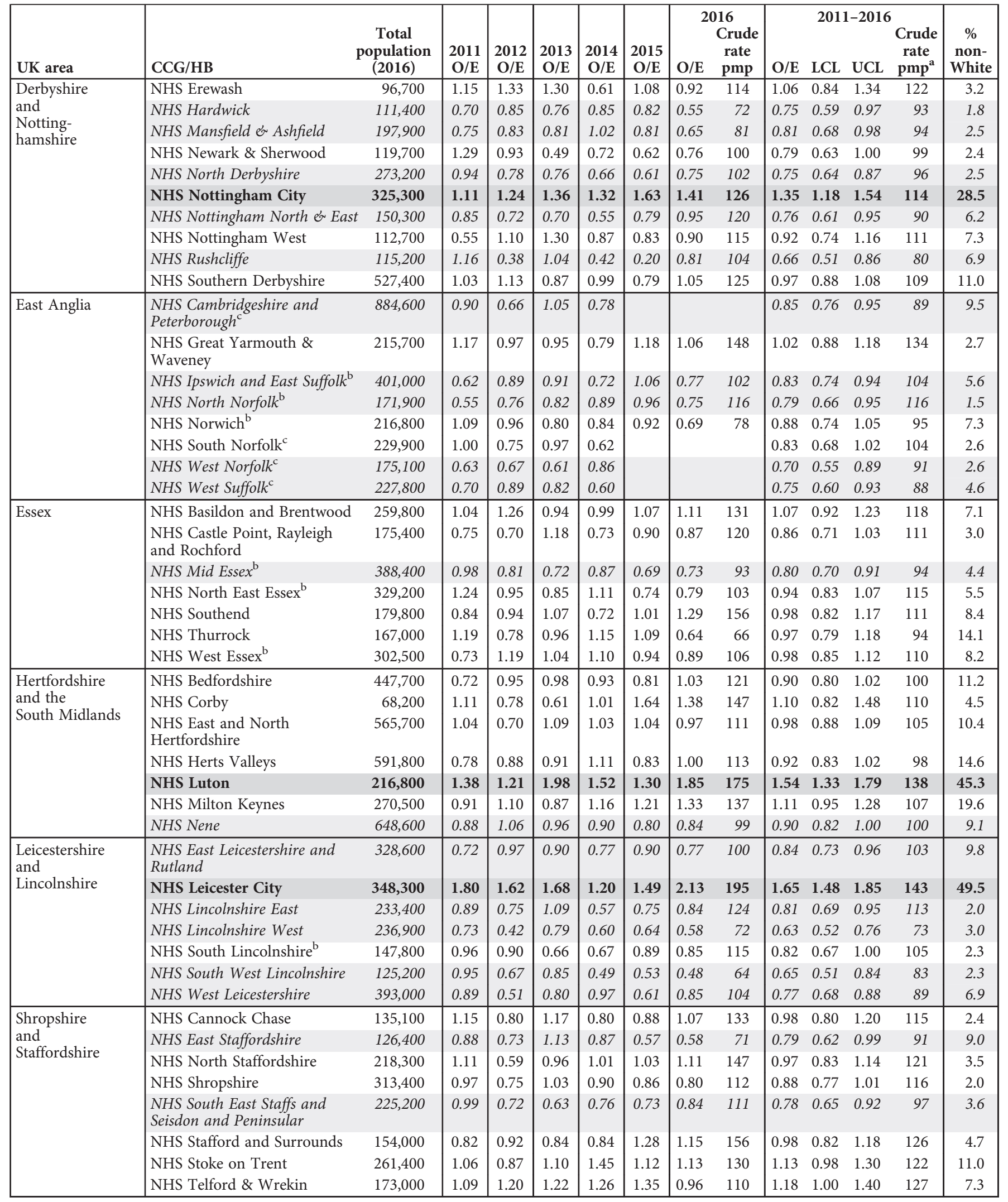


Table 1.3. Continued

\begin{tabular}{|c|c|c|c|c|c|c|c|c|c|c|c|c|c|c|}
\hline UK area & CCG/HB & $\begin{array}{c}\text { Total } \\
\text { population } \\
(2016)\end{array}$ & $\begin{array}{c}2011 \\
\mathrm{O} / \mathrm{E}\end{array}$ & $\begin{array}{c}2012 \\
\mathrm{O} / \mathrm{E}\end{array}$ & $\begin{array}{c}2013 \\
\mathrm{O} / \mathrm{E} \\
\end{array}$ & $\begin{array}{c}2014 \\
\mathrm{O} / \mathrm{E}\end{array}$ & $\begin{array}{l}2015 \\
\mathrm{O} / \mathrm{E}\end{array}$ & $\mathrm{O} / \mathrm{E}$ & $\begin{array}{l}\text { Crude } \\
\text { rate } \\
\text { pmp }\end{array}$ & $\mathrm{O} / \mathrm{E}$ & 2011 & -2016 & $\begin{array}{l}\text { Crude } \\
\text { rate } \\
\text { pmp }^{\text {a }}\end{array}$ & $\begin{array}{c}\% \\
\text { non- } \\
\text { White }\end{array}$ \\
\hline \multirow{19}{*}{ London } & NHS Barnet & 386,100 & 1.41 & 1.46 & 1.23 & 1.29 & 1.41 & 1.27 & 130 & 1.34 & 1.20 & 1.50 & 129 & 35.9 \\
\hline & NHS Camden & 246,200 & 1.11 & 1.06 & 1.32 & 1.16 & 1.28 & 0.99 & 93 & 1.15 & 0.98 & 1.35 & 103 & 33.7 \\
\hline & NHS City and Hackney & 282,900 & 1.68 & 2.02 & 1.83 & 2.11 & 1.13 & 1.84 & 148 & 1.76 & 1.55 & 2.01 & 134 & 44.6 \\
\hline & NHS Haringey & 278,500 & 1.69 & 2.27 & 2.21 & 1.64 & 1.56 & 1.94 & 172 & 1.88 & 1.66 & 2.12 & 157 & 39.5 \\
\hline & NHS Havering & 252,800 & 1.20 & 1.04 & 0.83 & 0.92 & 1.08 & 0.78 & 91 & 0.97 & 0.83 & 1.13 & 106 & 12.3 \\
\hline & NHS Islington & 232,900 & 1.53 & 2.05 & 1.44 & 1.11 & 1.60 & 1.06 & 90 & 1.46 & 1.25 & 1.70 & 117 & 31.8 \\
\hline & NHS Newham & 341,000 & 2.12 & 1.86 & 2.14 & 2.24 & 2.31 & 2.44 & 191 & 2.19 & 1.97 & 2.44 & 161 & 71.0 \\
\hline & NHS Redbridge & 299,200 & 1.38 & 2.15 & 1.98 & 1.45 & 1.45 & 1.73 & 167 & 1.68 & 1.50 & 1.90 & 153 & 57.5 \\
\hline & NHS Ealing & 343,200 & 1.91 & 2.26 & 1.68 & 1.78 & 2.25 & 1.77 & 175 & 1.94 & 1.76 & 2.15 & 181 & 51.0 \\
\hline & $\begin{array}{l}\text { NHS Hammersmith and } \\
\text { Fulham }\end{array}$ & 179,700 & 1.43 & 1.49 & 0.99 & 1.44 & 1.13 & 1.80 & 167 & 1.38 & 1.16 & 1.64 & 121 & 31.9 \\
\hline & NHS Harrow & 248,800 & 2.23 & 1.59 & 1.06 & 1.54 & 1.43 & 1.70 & 185 & 1.59 & 1.40 & 1.80 & 162 & $\mathbf{5 7 . 8}$ \\
\hline & NHS Hillingdon & 302,500 & 1.46 & 1.50 & 1.42 & 1.00 & 1.08 & 1.16 & 116 & 1.26 & 1.10 & 1.44 & 118 & 39.4 \\
\hline & NHS Hounslow & 271,100 & 1.83 & 1.73 & 2.02 & 1.28 & 1.29 & 1.65 & 159 & 1.62 & 1.43 & 1.84 & 147 & 48.6 \\
\hline & $\begin{array}{l}\text { NHS West London } \\
\text { (Kensington and Chelsea, } \\
\text { Queen's Park and Paddington) }\end{array}$ & 226,000 & 1.20 & 0.91 & 0.98 & 1.50 & 0.67 & 1.23 & 128 & 1.08 & 0.92 & 1.27 & 106 & 33.4 \\
\hline & NHS Bexley & 244,800 & 1.17 & 0.87 & 1.01 & 1.11 & 1.24 & 1.65 & 184 & 1.19 & 1.03 & 1.37 & 124 & 18.1 \\
\hline & NHS Richmond & 195,800 & 0.69 & 0.79 & 0.98 & 0.78 & 0.60 & 0.65 & 71 & 0.74 & 0.61 & 0.92 & 77 & 14.0 \\
\hline & NHS Southwark & 313,200 & 1.96 & 1.74 & 2.23 & 1.82 & 1.83 & 1.69 & 144 & 1.88 & 1.67 & 2.11 & 150 & 45.8 \\
\hline & NHS Sutton & 202,200 & 1.30 & 1.54 & 0.80 & 1.66 & 1.40 & 1.41 & 153 & 1.36 & 1.17 & 1.58 & 138 & 21.4 \\
\hline & NHS Wandsworth & 316,100 & 1.23 & 1.39 & 0.96 & 1.56 & 1.77 & 1.38 & 120 & 1.39 & 1.22 & 1.59 & 114 & 28.6 \\
\hline \multirow{4}{*}{$\begin{array}{l}\text { Bath, } \\
\text { Gloucestershire, } \\
\text { Swindon } \\
\text { and Wiltshire }\end{array}$} & $\begin{array}{l}\text { NHS Bath and North East } \\
\text { Somerset }\end{array}$ & 187,800 & 0.56 & 0.92 & 0.95 & 0.66 & 0.59 & 0.73 & 85 & 0.73 & 0.60 & 0.90 & 81 & 5.4 \\
\hline & NHS Gloucestershire & 623,100 & 0.88 & 1.17 & 0.70 & 0.92 & 0.87 & 0.86 & 111 & 0.90 & 0.81 & 0.99 & 109 & 4.6 \\
\hline & NHS Swindon & 223,600 & 1.14 & 1.22 & 0.92 & 1.16 & 1.15 & 1.08 & 121 & 1.11 & 0.95 & 1.30 & 117 & 10.0 \\
\hline & NHS Wiltshire & 488,400 & 0.64 & 0.47 & 0.77 & 0.81 & 0.69 & 0.83 & 106 & 0.71 & 0.62 & 0.80 & 85 & 3.4 \\
\hline \multirow{4}{*}{$\begin{array}{l}\text { Bristol, North } \\
\text { Somerset, } \\
\text { Somerset and } \\
\text { South } \\
\text { Gloucestershire } \\
\end{array}$} & NHS Bristol & 454,200 & 1.44 & 1.26 & 1.38 & 1.16 & 1.20 & 1.30 & 125 & 1.29 & 1.15 & 1.44 & 117 & 16.0 \\
\hline & NHS North Somerset & 211,700 & 0.87 & 1.02 & 1.04 & 1.01 & 0.79 & 0.77 & 104 & 0.91 & 0.78 & 1.07 & 117 & 2.7 \\
\hline & NHS Somerset & 549,400 & 0.84 & 0.67 & 0.55 & 0.88 & 0.66 & 0.86 & 118 & 0.75 & 0.67 & 0.83 & 96 & 2.0 \\
\hline & NHS South Gloucestershire & 277,600 & 0.61 & 0.81 & 1.15 & 0.68 & 0.74 & 0.81 & 97 & 0.80 & 0.68 & 0.94 & 91 & 5.0 \\
\hline \multirow{3}{*}{$\begin{array}{l}\text { Devon, } \\
\text { Cornwall and } \\
\text { Isles of Scilly }\end{array}$} & NHS Kernow & 556,000 & 0.81 & 0.95 & 0.88 & 0.79 & 1.01 & 0.90 & 126 & 0.89 & 0.81 & 0.99 & 117 & 1.8 \\
\hline & NHS North, East, West Devon & 898,000 & 0.92 & 1.00 & 0.84 & 0.92 & 0.90 & 0.87 & 115 & 0.91 & 0.84 & 0.98 & 112 & 3.0 \\
\hline & NHS South Devon and Torbay & $\quad 279,900$ & 0.90 & 1.08 & 1.00 & 0.87 & 0.88 & 0.98 & 143 & 0.95 & 0.83 & 1.08 & 130 & 2.1 \\
\hline
\end{tabular}


Table 1.3. Continued

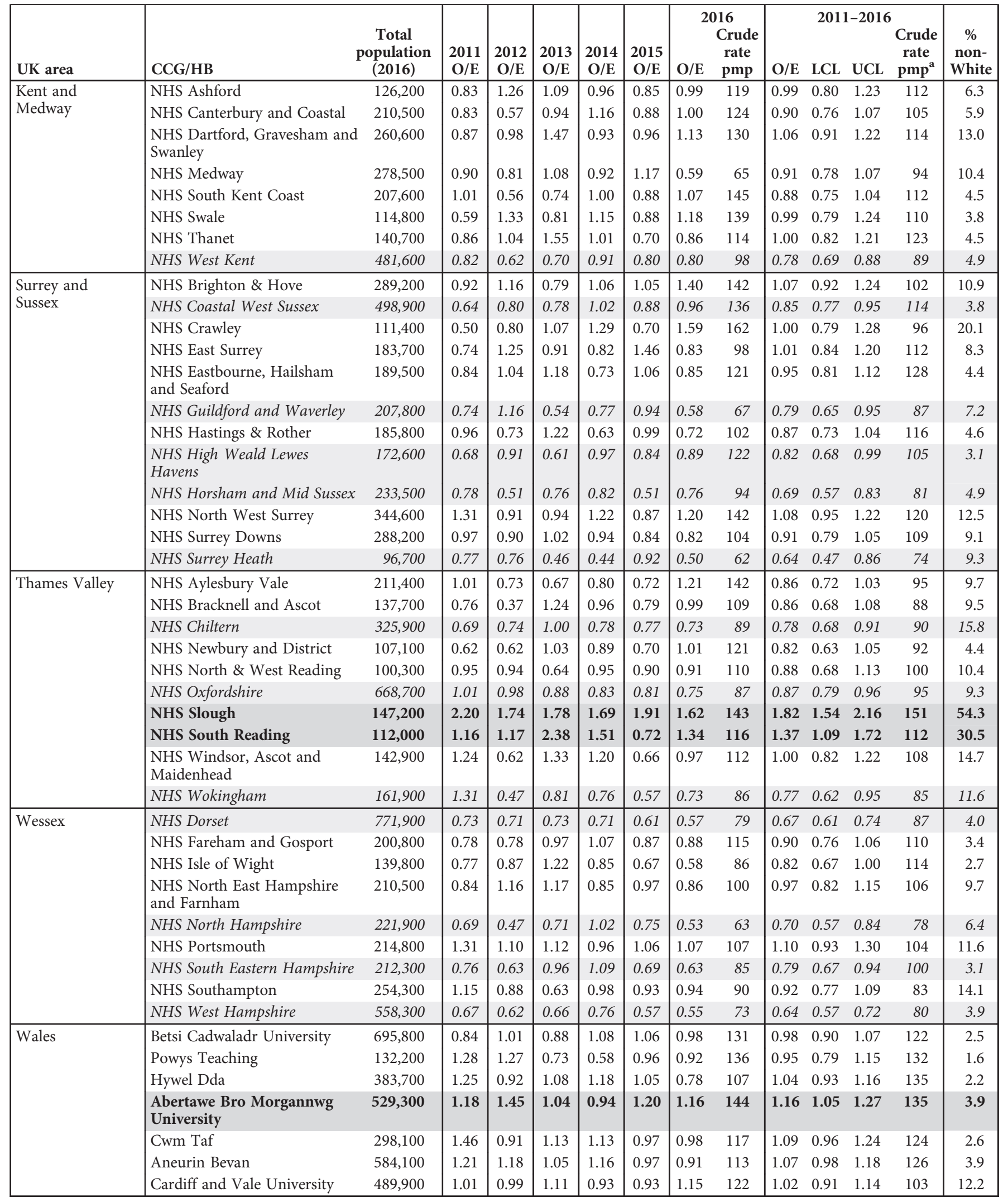


Table 1.3. Continued

\begin{tabular}{|c|c|c|c|c|c|c|c|c|c|c|c|c|c|c|}
\hline UK area & CCG/HB & $\begin{array}{c}\text { Total } \\
\text { population } \\
(2016) \\
\end{array}$ & $\begin{array}{c}2011 \\
\mathrm{O} / \mathrm{E} \\
\end{array}$ & $\begin{array}{c}2012 \\
\mathrm{O} / \mathrm{E} \\
\end{array}$ & $\begin{array}{c}2013 \\
\mathrm{O} / \mathrm{E} \\
\end{array}$ & $\begin{array}{c}2014 \\
\mathrm{O} / \mathrm{E} \\
\end{array}$ & $\begin{array}{c}2015 \\
\mathrm{O} / \mathrm{E} \\
\end{array}$ & $\mathbf{O} / \mathbf{E}$ & $\begin{array}{l}\text { Crude } \\
\text { rate } \\
\text { pmp }\end{array}$ & $\mathrm{O} / \mathrm{E}$ & LCL & $1-201$ & $\begin{array}{c}\text { Crude } \\
\text { rate } \\
\text { pmp }^{\mathrm{a}}\end{array}$ & $\begin{array}{c}\% \\
\text { non- } \\
\text { White }\end{array}$ \\
\hline \multirow[t]{14}{*}{\begin{tabular}{|l|} 
Scotland \\
\end{tabular}} & Ayrshire and Arran & 370,600 & 0.83 & 0.96 & 1.00 & 0.80 & 0.90 & 1.21 & 162 & 0.95 & 0.85 & 1.07 & 120 & 1.2 \\
\hline & Borders & 114,500 & 0.56 & 0.56 & 0.47 & 0.57 & 0.67 & 0.31 & 44 & 0.52 & 0.39 & 0.69 & 70 & 1.3 \\
\hline & Dumfries and Galloway & 149,500 & 0.58 & 1.05 & 0.41 & 1.20 & 0.64 & 0.51 & 74 & 0.73 & 0.59 & 0.90 & 99 & 1.2 \\
\hline & Fife & 370,300 & 1.17 & 0.87 & 1.01 & 0.91 & 1.04 & 0.71 & 89 & 0.95 & 0.84 & 1.07 & 113 & 2.4 \\
\hline & Forth Valley & 304,500 & 0.82 & 0.88 & 1.00 & 0.92 & 1.01 & 0.61 & 76 & 0.87 & 0.75 & 1.01 & 101 & 2.2 \\
\hline & Grampian & 588,100 & 0.83 & 0.86 & 0.91 & 0.76 & 0.88 & 0.80 & 95 & 0.84 & 0.75 & 0.94 & 94 & 4.0 \\
\hline & Greater Glasgow and Clyde & $1,161,400$ & 1.11 & 1.13 & 0.93 & 0.90 & 1.14 & 1.09 & 124 & 1.05 & 0.98 & 1.12 & 113 & 7.3 \\
\hline & Highland & 321,900 & 0.52 & 0.62 & 0.68 & 0.52 & 0.93 & 0.59 & 81 & 0.65 & 0.55 & 0.75 & 83 & 1.3 \\
\hline & Lanarkshire & 656,500 & 0.84 & 1.08 & 0.93 & 0.89 & 0.94 & 0.97 & 117 & 0.94 & 0.86 & 1.04 & 107 & 2.0 \\
\hline & Lothian & 880,000 & 0.71 & 0.74 & 0.60 & 0.75 & 0.70 & 0.72 & 81 & 0.70 & 0.64 & 0.78 & 74 & 5.6 \\
\hline & Orkney & 21,900 & 0.00 & 1.85 & 0.72 & 0.00 & 1.62 & 0.00 & 0 & 0.69 & 0.39 & 1.22 & 92 & 0.7 \\
\hline & Shetland & 23,200 & 0.78 & 0.00 & 0.75 & 1.06 & 1.02 & 0.68 & 86 & 0.73 & 0.41 & 1.28 & 86 & 1.5 \\
\hline & Tayside & 415,500 & 1.20 & 0.68 & 0.87 & 0.96 & 0.95 & 0.86 & 111 & 0.92 & 0.82 & 1.03 & 111 & 3.2 \\
\hline & Western Isles & 26,900 & 0.00 & 0.00 & 0.85 & 1.60 & 1.79 & 1.03 & 149 & 0.91 & 0.59 & 1.42 & 124 & 0.9 \\
\hline \multirow{5}{*}{$\begin{array}{l}\text { Northern } \\
\text { Ireland }\end{array}$} & Belfast & 354,700 & 1.08 & 1.71 & 1.17 & 0.88 & 1.24 & 1.46 & 155 & 1.25 & 1.11 & 1.41 & 125 & 3.2 \\
\hline & Northern & 473,100 & 1.24 & 1.12 & 1.03 & 1.01 & 0.93 & 1.09 & 125 & 1.07 & 0.96 & 1.19 & 115 & 1.2 \\
\hline & Southern & 377,200 & 1.27 & 0.86 & 0.83 & 0.76 & 0.88 & 0.78 & 82 & 0.89 & 0.78 & 1.02 & 88 & 1.2 \\
\hline & South Eastern & 356,700 & 0.92 & 0.80 & 0.91 & 0.76 & 1.27 & 1.02 & 121 & 0.95 & 0.84 & 1.09 & 106 & 1.3 \\
\hline & Western & 300,400 & 0.97 & 0.59 & 0.97 & 1.05 & 1.15 & 1.10 & 120 & 0.98 & 0.85 & 1.13 & 100 & 1.0 \\
\hline
\end{tabular}

\footnotetext{
a - per year
}

${ }^{\mathrm{b}}$ CCGs where between 5\% and 15\% of the incident RRT population from 2011 to 2014 were incident patients of the Cambridge renal centre. In these CCGs the rates/ratios for 2015 and 2016 and for the combined years 2011-2016 are likely to be underestimated

${ }^{c}$ CCGs where $>15 \%$ of the incident RRT population from 2011 to 2014 were incident patients of the Cambridge renal centre. These have not been included in the analysis for 2015 or 2016 but are included for 2011-2014 (and the combined years analysis for these areas uses only four years (2011-2014))

between areas, with ratios ranging from 0.52 to 2.53 (IQR $0.82,1.09$ ). From the analysis using all six years (where available), out of a total of 233 areas, 44 areas had notably high ratios and 67 notably low. The crude rates ranged from $70 \mathrm{pmp}$ to $200 \mathrm{pmp}$ (IQR $96 \mathrm{pmp}, 121 \mathrm{pmp}$ ). These rates and ratios are not adjusted for population ethnicity, which correlates strongly with incidence at CCG/HB level (figure 1.3).

\section{Centre level}

The number of new patients starting RRT at each renal centre from 2011 to 2016 is shown in table 1.4. The table also shows centre level incidence rates (per million population) for 2016. For most centres there was a lot of variability in the numbers of incident patients from one year to the next, making it hard to see any underlying trend. Variation incorporates chance fluctuation, the introduction of new centres, changes in catchment populations and completeness of reporting.
Trends reflect changes in incidence of ERF (underlying disease prevalence, recognition and survival from comorbidity), and practice changes such as an emphasis

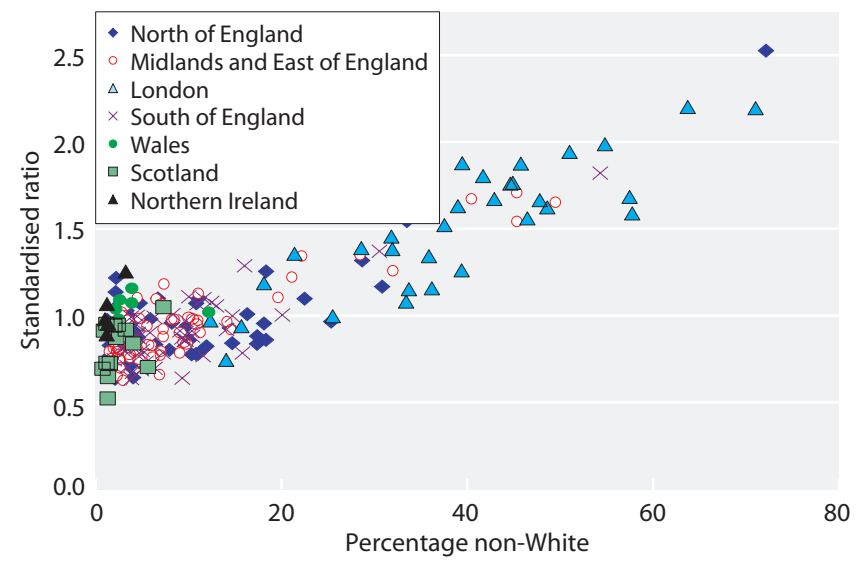

Fig. 1.3. Age/sex standardised incidence ratio (2011-2016) by percentage non-White 
Table 1.4. Number of patients starting RRT by renal centre 2011-2016

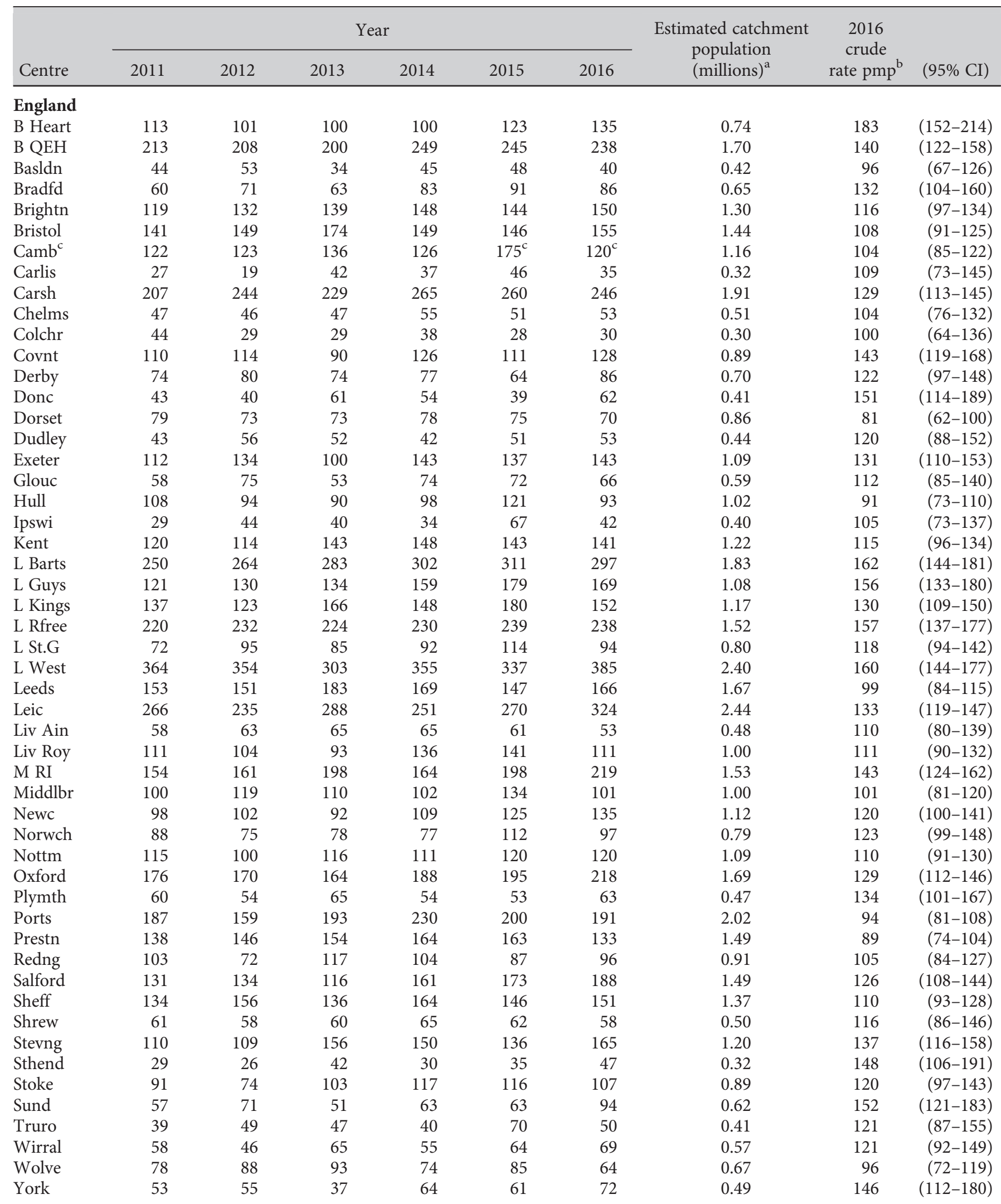


Table 1.4. Continued

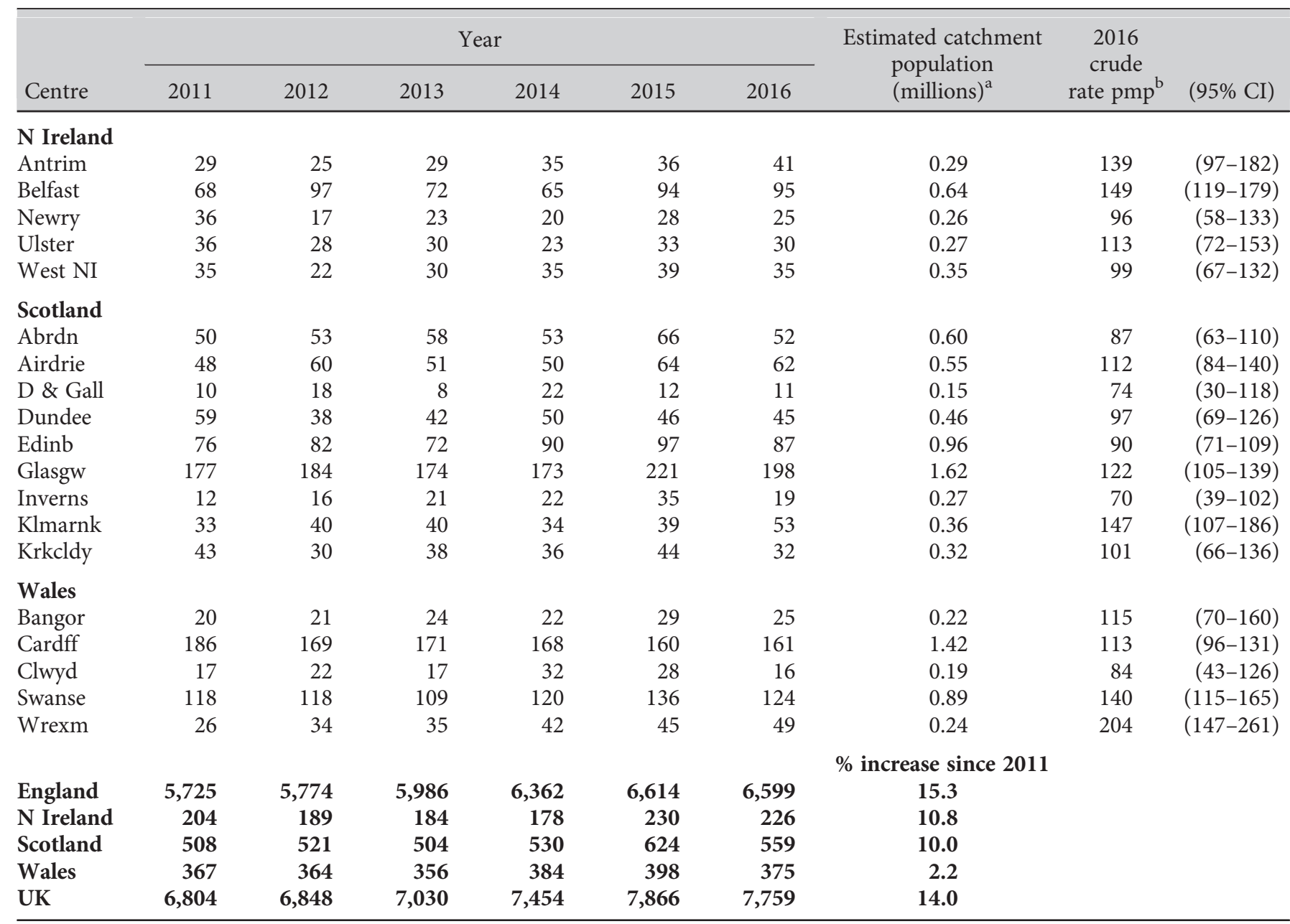

${ }^{a}$ See appendix E for details of estimation of catchment populations

${ }^{\mathrm{b}} \mathrm{pmp}$ - per million population

${ }^{c}$ Cambridge was unable to submit patient level data for 2015 or 2016 but provided the UKRR with information allowing their incident numbers for 2015 and 2016 to be estimated. These numbers have been used here and in table 1.2 but not elsewhere in this chapter

on pre-emptive transplantation or the introduction of conservative care programmes. Analysis of data from patients with chronic kidney disease (CKD) stage 5 who are not receiving RRT is required to explore these underlying mechanisms.

The number of people starting RRT in the UK increased between 2011 and 2016, with an overall rise of $14.0 \%$ over these six years.

\section{Demographics and clinical characteristics of patients starting RRT}

\section{Methods}

Age, sex, primary renal disease, ethnic origin and treatment modality were examined for patients starting RRT.
Crude CCG/HB incidence rates were calculated for the over 75 year age group. These are per million age related population (pmarp), i.e. the number of incident patients over 75 years old divided by the population over 75 years old.

A mixture of old and new (2012) ERA-EDTA codes for primary diagnoses [2] were received from centres. For those people without an old code, new codes (where available) were converted to old codes using the mapping available on the ERAEDTA website. As recommended in the notes for users in the ERA-EDTA's primary renal diagnosis (PRD) code list document, this mapping is provided for guidance only and has not been validated. These codes were grouped into the same eight categories as in previous reports, the details are given in appendix $\mathrm{H}$ : Ethnicity and ERA-EDTA Coding (www.renalreg.org).

Most centres electronically upload ethnicity coding to their renal information technology (IT) system from the hospital Patient Administration System (PAS). Ethnicity coding in these PAS systems was based on self-reported ethnicity. For the 
remaining centres, ethnicity coding was performed by clinical staff and recorded directly into the renal IT system (using a variety of coding systems). Data on ethnic origin were grouped into White, South Asian, Black, Chinese or Other. The details of regrouping of the PAS codes into the above ethnic categories are provided in appendix $\mathrm{H}$ : Ethnicity and ERA-EDTA Coding (www.renalreg.org). Chi-squared, Fisher's exact, ANOVA and Kruskal Wallis tests were used as appropriate.

Data were withheld from some tables due to small numbers of patients in a category that increase the possibility of identifying patients. Primary suppression is the withholding of information from risky cells for publication, which means that their value is not shown in the table but replaced by a symbol such as ' $x$ ' to indicate the suppression. According to the definition of a risky cell, in frequency count tables all cells containing small counts and in tables of magnitudes all cells containing small counts or presenting a case of dominance have to be primary suppressed. To reach the desired protection for risky cells, it is necessary to suppress additional non-risky cells, which is called complementary (secondary) suppression. The pattern of complementary suppressed cells has to be carefully chosen to provide the desired level of ambiguity for the risky cells with the least amount of suppressed information.

Estimated glomerular filtration rate (eGFR) at the start of RRT was studied amongst patients with eGFR data within 14 days before the start of RRT. The eGFR was calculated using the CKD-EPI equation [3]. The abbreviated four variable MDRD study equation was also used to allow comparison with values published in previous years. For the purpose of the eGFR calculation, patients who had missing ethnicity but a valid serum creatinine measurement were classed as White. The eGFR values were log transformed due to their skewed distribution and geometric means calculated.

\section{Results}

Incidence rates appear to have plateaued in the over 65 age group, but continued to rise amongst individuals between 45 and 64 years of age (figure 1.4). Figure 1.5 shows RRT incidence rates for 2016 by age group and sex. The peak rate was in the $80-84$ age group for men

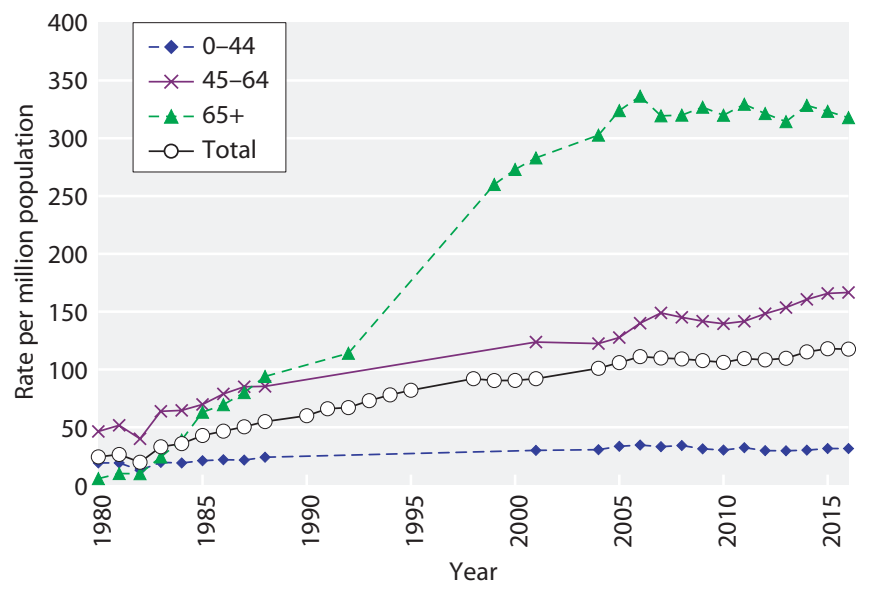

Fig. 1.4. RRT incidence rates between 1980 and 2016 and 75-79 for women. Figure 1.6 shows the numbers of people starting $\mathrm{HD}$ and $\mathrm{PD}$ by age group. The age group with the highest number of $\mathrm{HD}$ and PD starters was 65-74. Haemodialysis was used proportionately more, with increasing age above the age of 35 .

\section{Age}

In 2016, the median age of patients starting RRT was 64.3 years (table 1.5) and this has changed little over recent years. Per modality, the median age at start was 66.8 years for patients starting on HD, 60.5 for patients starting on PD and 50.5 for those having a pre-emptive transplant (table 1.6). The median age at start, of nonWhite patients, was 58.7, considerably lower than that for White patients (66.2 years) reflecting differences in $\mathrm{CKD}$ frequency and progression and the younger age distribution of ethnic minority populations in general, compared with the White population (in the 2011 census data for England and Wales, 5.3\% of ethnic minorities

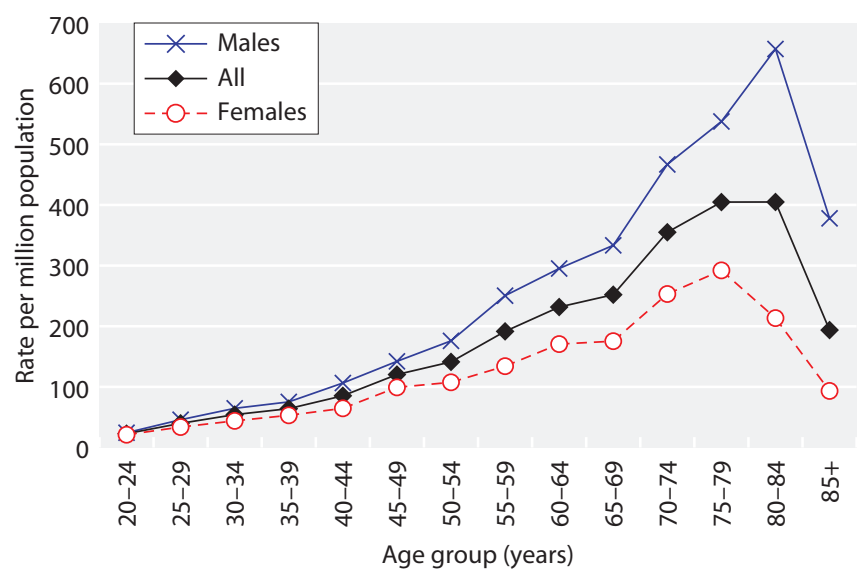

Fig. 1.5. RRT incidence rates in 2016 by age and sex

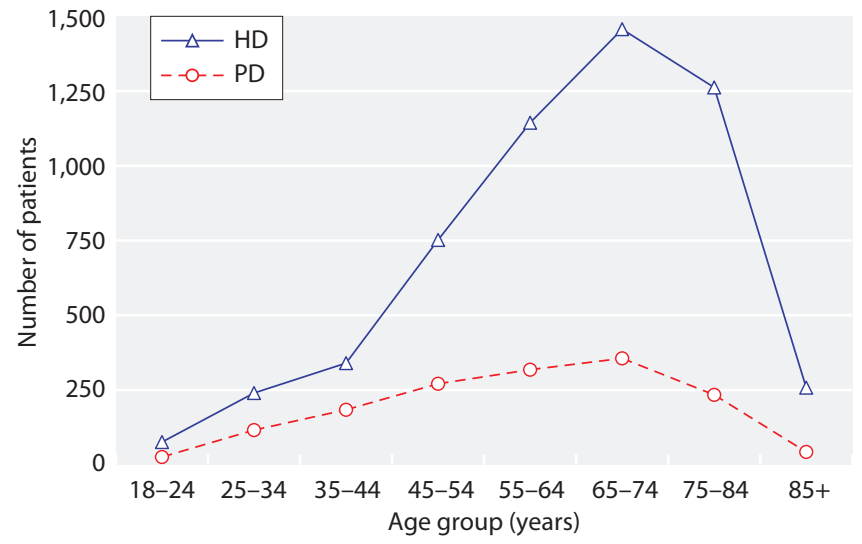

Fig. 1.6. Number of incident dialysis patients in 2016, by age group and initial dialysis modality 
were over 65 years old compared to $18.3 \%$ of Whites) [4]. The median age of new patients with diabetes was similar to the overall median and has not varied greatly over recent years.

There were large differences between centres in the median age of incident patients (figure 1.7). This is likely to reflect differences in the age and ethnic structure of the catchment populations (for which these data were not adjusted) along with chance, particularly in centres with small numbers of incident patients. Nevertheless, true practice variation may exist. The median age of patients

Table 1.5. Median, inter-quartile range and $90 \%$ range of the age of patients starting renal replacement therapy in 2016 by country

\begin{tabular}{lccc}
\hline Country & Median & IQR & 90\% range \\
\hline England & 64.3 & $(51.5-74.5)$ & $(31.4-84.1)$ \\
N Ireland & 66.0 & $(51.3-74.2)$ & $(34.5-82.9)$ \\
Scotland & 62.4 & $(49.9-72.9)$ & $(32.4-81.9)$ \\
Wales & 66.3 & $(55.4-76.5)$ & $(34.3-85.8)$ \\
UK & $\mathbf{6 4 . 3}$ & $\mathbf{( 5 1 . 6 - 7 4 . 5 )}$ & $\mathbf{( 3 1 . 9 - 8 4 . 0 )}$ \\
\hline
\end{tabular}

IQR - interquartile range

Table 1.6. Median, inter-quartile range and $90 \%$ range of the age of patients starting renal replacement therapy in 2016 by initial treatment modality

\begin{tabular}{lccc}
\hline Treatment & Median & IQR & $90 \%$ range \\
\hline HD & 66.8 & $(54.7-76.0)$ & $(34.0-84.7)$ \\
PD & 60.5 & $(47.3-72.0)$ & $(30.2-82.5)$ \\
Transplant & 50.5 & $(41.1-60.3)$ & $(26.6-70.5)$ \\
\hline
\end{tabular}

IQR - interquartile range starting treatment at transplant centres was 62.8 years (IQR 50.3, 73.3) and at non-transplanting centres 66.0 years (IQR 52.7, 75.5).

Averaged over 2011-2016, crude CCG/HB incidence rates in the over 75 year age group varied from 57 per million age related population (pmarp) in Borders to 1,048 pmarp in NHS Brent (IQR 259 pmarp, 400 pmarp, data not shown). The variation between CCG/HBs seen in the over 75 year age group was much greater than the variation seen in the overall analysis. Some of this difference is likely to be due to the smaller numbers included in the over 75 analysis.

Sex

More men than women started RRT in every age group and this sex effect appeared to increase with age (figure 1.8). The overall breakdown was $62.9 \%$ male, $37.1 \%$ female.

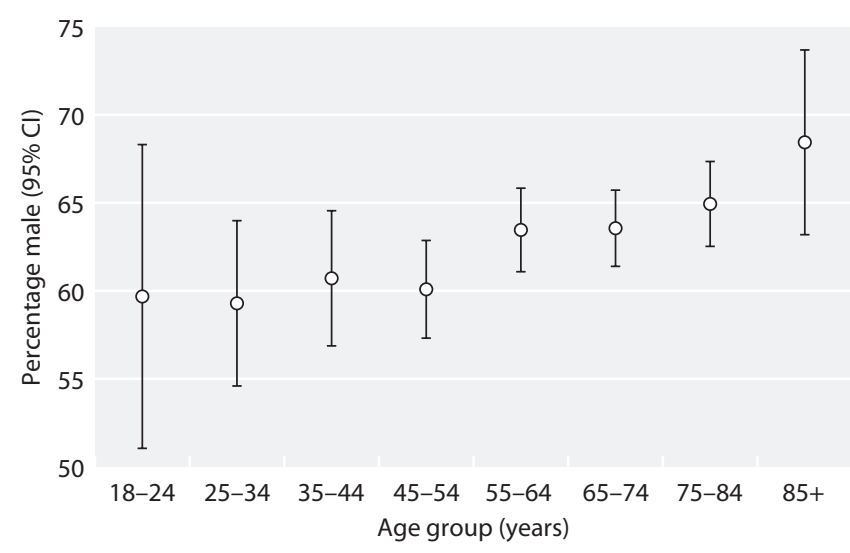

Fig. 1.8. Percentage of patients starting RRT in 2016 who were male, by age group

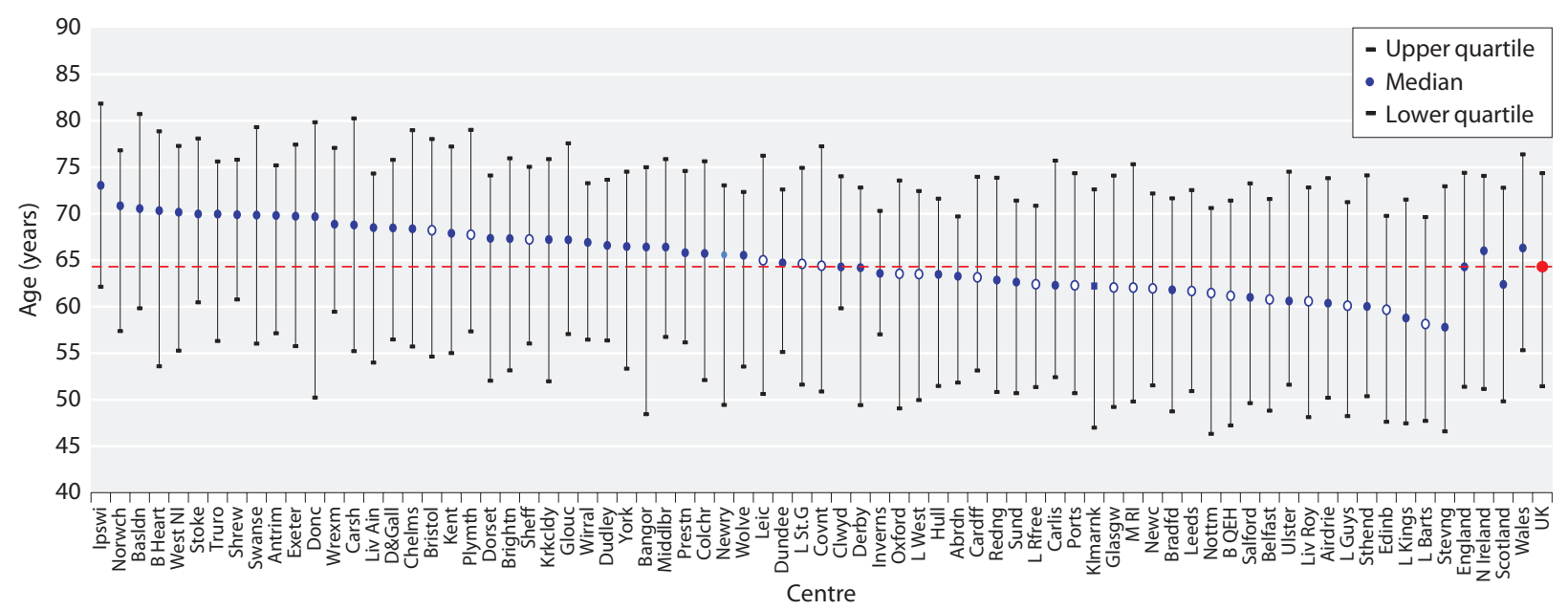

Fig. 1.7. Median age of incident RRT patients by centre in 2016 White points indicate transplant centres 


\section{Ethnicity}

As in previous reports, Scotland is not included in this section as completeness of ethnicity data was low. Across centres in England, Wales and Northern Ireland the average completeness was $94.9 \%$ for 2016 incident patients, similar to the $95.8 \%$ seen last year and the $94.8 \%$ the year before. Data completeness and the percentage in minority ethnic groups are shown by centre in table 1.7a. Table 1.7b shows the overall detailed ethnicity breakdown for England, Wales and Northern Ireland.

Table 1.7a. Percentage of incident patients (2016) in minority ethnic groups (South Asian, Black, Chinese or Other) by centre

\begin{tabular}{|c|c|c|c|c|c|c|c|}
\hline Centre & $\begin{array}{c}\text { Percentage } \\
\text { with data } \\
\text { not available }\end{array}$ & $\begin{array}{c}N \text { with } \\
\text { data }\end{array}$ & $\begin{array}{l}\text { Percentage } \\
\text { non-White }\end{array}$ & Centre & $\begin{array}{c}\text { Percentage } \\
\text { with data } \\
\text { not available }\end{array}$ & $\begin{array}{c}N \text { with } \\
\text { data }\end{array}$ & $\begin{array}{l}\text { Percentage } \\
\text { non-White }\end{array}$ \\
\hline England & & & & Nottm & 0.8 & 119 & 19 \\
\hline B Heart & 0.0 & 135 & 34 & Oxford & 20.2 & 174 & 20 \\
\hline B QEH & 3.8 & 229 & 40 & Plymth & 1.6 & 62 & $*$ \\
\hline Basldn & 5.0 & 38 & 18 & Ports & 15.7 & 161 & $*$ \\
\hline Bradfd & 1.2 & 85 & 40 & Prestn & 0.0 & 133 & 16 \\
\hline Brightn & 10.7 & 134 & $*$ & Redng & 15.6 & 81 & 23 \\
\hline Bristol & 19.4 & 125 & 12 & Salford & 3.2 & 182 & 21 \\
\hline Carlis & 2.9 & 34 & $*$ & Sheff & 2.6 & 147 & $*$ \\
\hline Carsh & 8.9 & 224 & 29 & Shrew & 3.4 & 56 & $*$ \\
\hline Chelms & 0.0 & 53 & $*$ & Stevng & 14.5 & 141 & 26 \\
\hline Colchr & 3.3 & 29 & $*$ & Sthend & 0.0 & 47 & 19 \\
\hline Covnt & 3.1 & 124 & 19 & Stoke & 9.3 & 97 & $*$ \\
\hline Derby & 1.2 & 85 & 11 & Sund & 0.0 & 94 & $*$ \\
\hline Donc & 0.0 & 62 & $*$ & Truro & 0.0 & 50 & $*$ \\
\hline Dorset & 1.4 & 69 & $*$ & Wirral & 2.9 & 67 & $*$ \\
\hline Dudley & 0.0 & 53 & 25 & Wolve & 0.0 & 64 & 30 \\
\hline Exeter & 1.4 & 141 & $*$ & York & 6.9 & 67 & $*$ \\
\hline Glouc & 1.5 & 65 & * & & & & \\
\hline Hull & 2.2 & 91 & * & N Ireland & & & \\
\hline Ipswi & 7.1 & 39 & 26 & Antrim & 0.0 & 41 & $*$ \\
\hline Kent & 2.1 & 138 & $*$ & Belfast & 17.9 & 78 & $*$ \\
\hline L Barts & 0.3 & 296 & 69 & Newry & 0.0 & 25 & $*$ \\
\hline L Guys & 5.3 & 160 & $\begin{array}{l}09 \\
43\end{array}$ & Ulster & 0.0 & 30 & $*$ \\
\hline L Kings & 0.0 & 152 & $\begin{array}{l}45 \\
48\end{array}$ & West NI & 2.9 & 34 & $*$ \\
\hline L Rfree & 5.0 & 226 & 53 & Wales & & & \\
\hline L St.G & 14.9 & 80 & 54 & Bangor & 12.0 & 22 & $*$ \\
\hline L West & 0.0 & 385 & 59 & $\begin{array}{l}\text { Bangor } \\
\text { Cardff }\end{array}$ & $\begin{array}{r}12.0 \\
3.7\end{array}$ & 155 & $*$ \\
\hline Leeds & 0.6 & 165 & 25 & Clwyd & $\begin{array}{r}J .7 \\
18.8\end{array}$ & 13 & * \\
\hline Leic & 9.0 & 295 & 23 & $\begin{array}{l}\text { Swanse } \\
\text { Swanse }\end{array}$ & $\begin{array}{r}10.0 \\
0.0\end{array}$ & 124 & * \\
\hline Liv Ain & 1.9 & 52 & $*$ & Wrexm & 6.1 & 46 & $*$ \\
\hline Liv Roy & 2.7 & 108 & 11 & & & & \\
\hline M RI & 4.1 & 210 & 30 & England & 5.0 & 6,153 & 25 \\
\hline Middlbr & 2.0 & 99 & $*$ & N Ireland & 8.0 & 208 & $*$ \\
\hline Newc & 0.0 & 135 & * & Wales & 4.0 & 360 & $*$ \\
\hline Norwch & 2.1 & 95 & $*$ & E, W \& NI & 5.1 & 6,721 & 23 \\
\hline
\end{tabular}

$*<10 \%$ in minority ethnic group

Table 1.7b. Percentage of incident RRT patients (2016) in different ethnic groups (England, Wales and Northern Ireland)

\begin{tabular}{lccccccc} 
& \multirow{2}{*}{$\begin{array}{c}\text { \% data not } \\
\text { available }\end{array}$} & $\begin{array}{c}\text { N with } \\
\text { data }\end{array}$ & White & South Asian & Black & Chinese & Other \\
\cline { 4 - 9 } E, W \& NI & 5.1 & 6,721 & 76.8 & 12.1 & 7.4 & 0.5 & 3.2 \\
\hline
\end{tabular}

E, W \& NI - England, Wales, Northern Ireland 
Table 1.8a. Distribution of primary renal diagnosis by country in the 2012-2016 incident RRT cohort

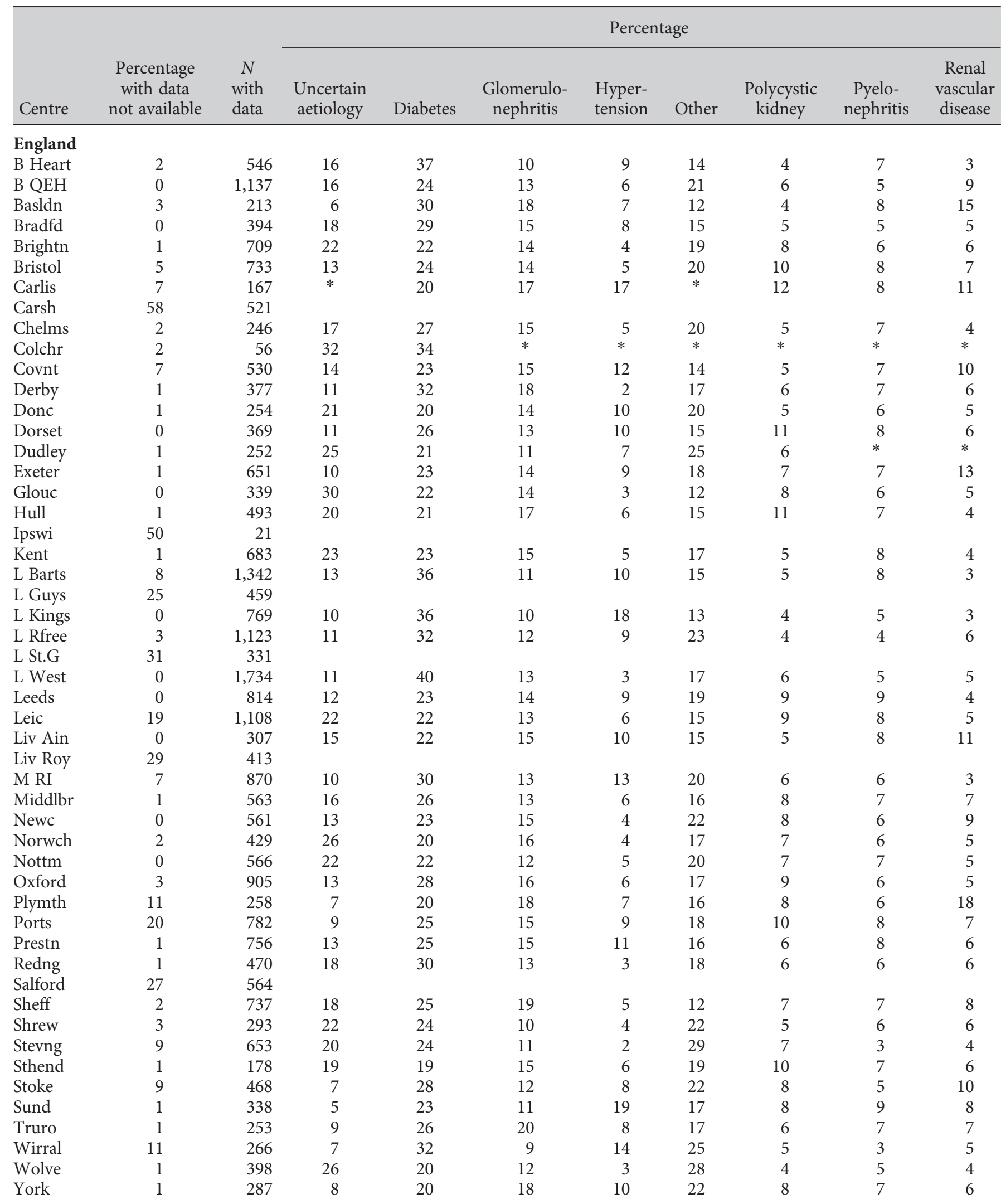


Table 1.8a. Continued

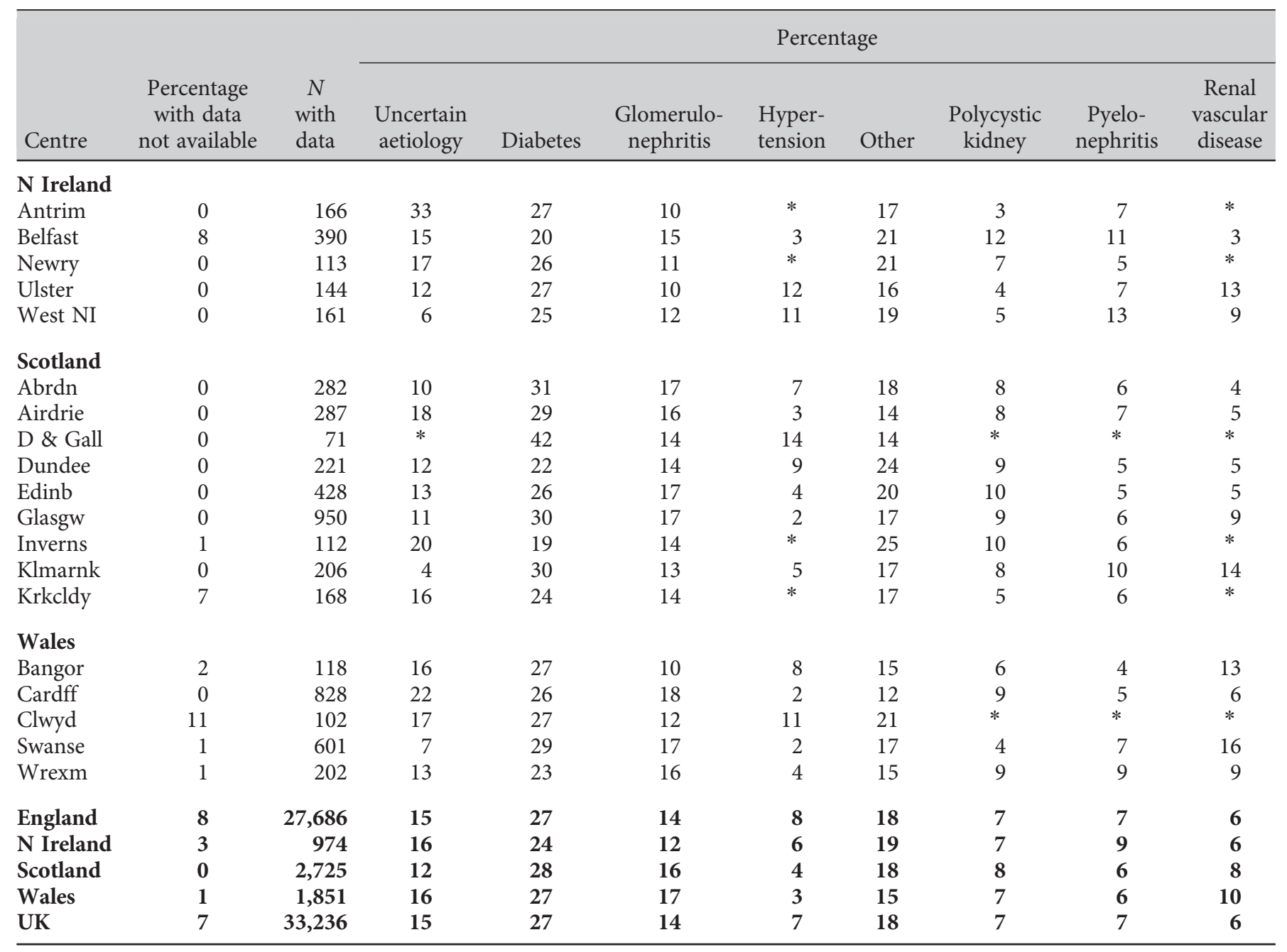

*values suppressed due to small numbers (primary or secondary suppression - see methods)

The percentage in each category has been calculated after excluding those patients with data not available

Blank cells - centres with $>25 \%$ missing primary diagnoses, the percentages in the other diagnostic categories have not been calculated For those centres judged to have high $\%$ uncertain aetiology for a year (arbitrarily defined as $>45 \%$ ), their data has not been used for that year

\section{Primary renal diagnosis}

The breakdown of PRD by centre is shown for a 2012-2016 incident cohort in table 1.8a. The breakdown by country is shown for 2016 incident patients in table 1.8 b. For completeness data for 2016 by centre see the Introduction chapter of this report. Fifty-four centres provided data on over $90 \%$ of incident patients and 31 of these centres had $100 \%$ completeness. There was only a small amount of missing data for Northern Ireland, Scotland and Wales, whilst England had 12.5\% missing. The overall percentage missing was $11.1 \%$ and this was similar in the under 65-year olds and those aged 65 and over (10.8\% and $11.3 \%$ respectively). Eight centres had missing PRD for more than 25\% of incident patients.

The UKRR continues to be concerned about centres with apparently very high data completeness for PRD, but also very high rates of 'uncertain' diagnoses (EDTA code 00: chronic renal failure; aetiology uncertain). It is accepted that there will inevitably be patients with uncertain aetiology. The proportion of these patients will vary between clinicians and centres in part because the diagnostic criteria of conditions such as hypertensive renal disease permit subjectivity. Many of the new ERA- 
Table 1.8b. Distribution of primary renal diagnosis by country in the 2016 incident RRT cohort

\begin{tabular}{|c|c|c|c|c|c|c|c|c|c|c|}
\hline \multirow[b]{2}{*}{ Country } & \multirow[b]{2}{*}{$\begin{array}{c}\% \\
\text { data not } \\
\text { available }\end{array}$} & \multirow[b]{2}{*}{$\begin{array}{c}N \\
\text { with } \\
\text { data }\end{array}$} & \multicolumn{8}{|c|}{ Percentage } \\
\hline & & & $\begin{array}{l}\text { Uncertain } \\
\text { aetiology }\end{array}$ & Diabetes & $\begin{array}{c}\text { Glomerulo- } \\
\text { nephritis }\end{array}$ & $\begin{array}{l}\text { Hyper- } \\
\text { tension }\end{array}$ & Other & $\begin{array}{l}\text { Polycystic } \\
\text { kidney }\end{array}$ & $\begin{array}{c}\text { Pyelo- } \\
\text { nephritis }\end{array}$ & $\begin{array}{c}\text { Renal } \\
\text { vascular } \\
\text { disease }\end{array}$ \\
\hline England & 12.5 & 5,669 & 14.9 & 28.7 & 13.0 & 7.0 & 17.0 & 6.9 & 6.4 & 6.1 \\
\hline N Ireland & 4.0 & 217 & 16.6 & 25.4 & 12.0 & 2.3 & 22.1 & 6.5 & 6.9 & 8.3 \\
\hline UK & 11.1 & 6,796 & 14.6 & 28.6 & 13.5 & 6.3 & 17.2 & 7.0 & 6.4 & 6.5 \\
\hline
\end{tabular}

The percentage in each category has been calculated after excluding those patients with data not available

EDTA codes allow clinicians to indicate the basis for the diagnosis of the PRD (e.g. biopsy-proven, or not). Adoption of these codes should reduce 'uncertain' PRD coding. There was wide variation in all PRD codes between centres.

The UK age distribution of PRDs is shown in table 1.9. Diabetic nephropathy was the most common renal diagnosis overall and in all age groups except the under 35s and those over 85. Glomerulonephritis and autosomal dominant polycystic kidney disease (ADPKD) made up much higher proportions of the younger than the older incident cohorts, whilst patients with renal vascular disease comprised a much higher percentage of the older rather than the younger patients. Aetiological uncertainty increased with age.

Table 1.10 shows the incidence rates for each PRD per million population for the 2016 cohort. As there were some missing data, the rates for at least some of the diagnoses will be underestimates.
First established treatment modality

In 2016, the first treatment recorded, irrespective of any later change, was haemodialysis in $72.4 \%$ of patients, peritoneal dialysis in $20.3 \%$ and pre-emptive transplant in $7.4 \%$ (table 1.11). The percentage having a pre-emptive transplant fell in 2015, however, about half of the apparent drop was due to Cambridge (a transplant centre) not being included in the data for 2015 or 2016 . Table F.1.3 in appendix F: Additional Data Tables for 2016 new and existing patients gives the treatment breakdown at start of RRT by centre.

Many patients undergo a period of HD before switches to other modalities are, or can be, considered. The modality in use at 90 days may be more representative of the first elective modality and is adopted for the remainder of this section. For these analyses, the incident cohort from 1 October 2015 to 30 September 2016 was used so that follow up to 90 days was possible for all patients. By 90 days, $4.0 \%$ of incident patients had died

Table 1.9. Percentage distribution of primary renal diagnosis by age in the 2016 incident RRT cohort

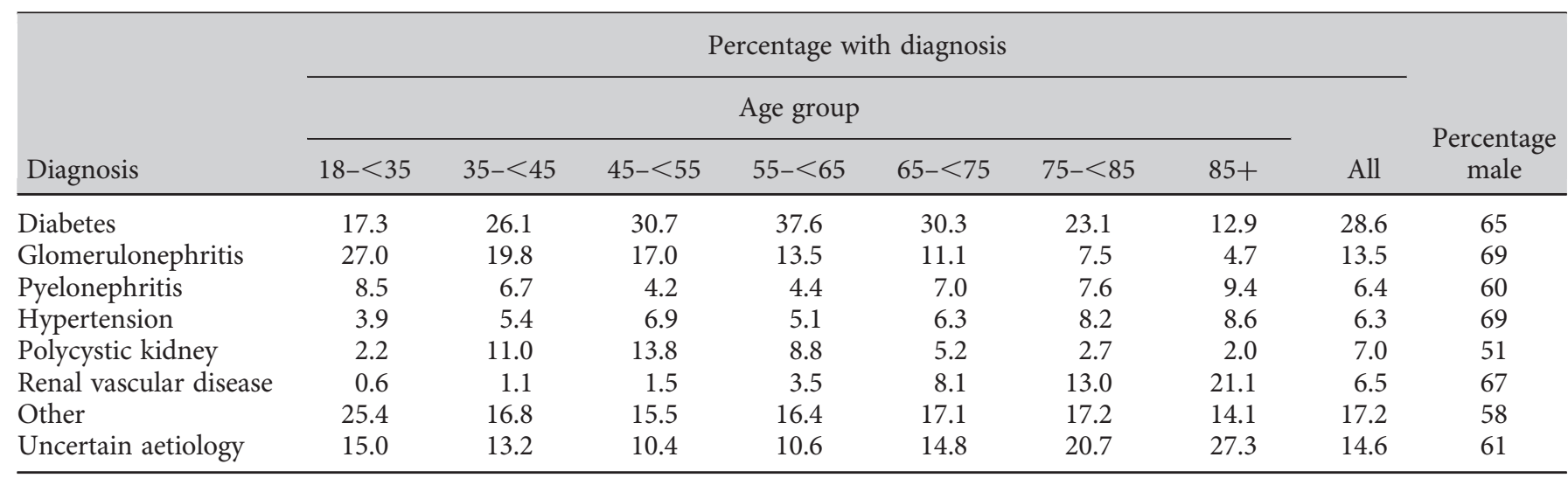

Percentages calculated after excluding those patients with data not available 
Table 1.10. Primary renal diagnosis RRT incidence rates (2016) per million population (unadjusted)

\begin{tabular}{|c|c|c|c|c|c|}
\hline Diagnosis & England & N Ireland & Scotland & Wales & UK \\
\hline Glomerulonephritis & 13.6 & 14.0 & 17.2 & 19.3 & 14.2 \\
\hline Hypertension & 7.3 & 2.7 & 3.9 & 3.5 & 6.7 \\
\hline Polycystic kidney & 7.3 & 7.5 & 7.4 & 8.4 & 7.3 \\
\hline Renal vascular disease & 6.4 & 9.7 & 8.5 & 10.3 & 6.8 \\
\hline Data not available & 15.0 & 4.8 & 2.2 & 3.9 & 13.1 \\
\hline All & 120 & 121 & 103 & 120 & 119 \\
\hline
\end{tabular}

The overall rates per country may be slightly different to those in table 1.2 as Cambridge (due to missing data) and Colchester (due to high percentage with uncertain aetiology) have been excluded from both the numerator and the denominator here

Table 1.11. Treatment at start and at 90 days by year of start

\begin{tabular}{lccc}
\hline Start & $\begin{array}{c}\text { HD } \\
(\%)\end{array}$ & $\begin{array}{c}\text { PD } \\
(\%)\end{array}$ & $\begin{array}{c}\text { Transplant } \\
(\%)\end{array}$ \\
\hline Day 0 treatment & & & \\
2011 & 72.7 & 20.4 & 6.9 \\
2012 & 72.8 & 19.5 & 7.7 \\
2013 & 71.9 & 19.3 & 8.8 \\
2014 & 71.9 & 19.9 & 8.3 \\
2015 & 73.0 & 19.3 & 7.7 \\
2016 & 72.4 & 20.3 & 7.4 \\
Day 90 treatment & & & \\
Oct 2010 to end Sept 2011 & 70.9 & 20.5 & 8.6 \\
Oct 2011 to end Sept 2012 & 70.9 & 20.1 & 9.0 \\
Oct 2012 to end Sept 2013 & 70.0 & 19.9 & 10.2 \\
Oct 2013 to end Sept 2014 & 69.7 & 20.1 & 10.2 \\
Oct 2014 to end Sept 2015 & 71.3 & 19.4 & 9.3 \\
Oct 2015 to end Sept 2016 & 69.8 & 20.5 & 9.7 \\
\hline
\end{tabular}

and a further $0.6 \%$ had stopped treatment, leaving 95.4\% of the original cohort still on RRT. Table 1.12a shows the percentages on each treatment modality at 90 days both as percentages of all of those starting RRT and then of those still on treatment at 90 days. Expressed as percentages of the whole incident cohort, $66.5 \%$ were on HD at 90 days, $19.6 \%$ were on PD and $9.3 \%$ had received a transplant. Expressed as percentages of those still receiving RRT at 90 days, $69.8 \%$ were on $\mathrm{HD}, 20.5 \%$ on PD and 9.7\% had received a transplant.

Figure 1.9 shows the modality breakdown with the HD patients further subdivided. Of those still on RRT at 90 days, $41 \%$ were treated with hospital HD, $28 \%$ with satellite $\mathrm{HD}$, and only $0.4 \%$ were receiving home $\mathrm{HD}$ at this early stage, equating to 32 patients (across 15 centres).

Table 1.12b shows the treatment breakdown at 90 days by centre for a five year cohort (1 October 2011 to 30 September 2016). Using just 2016 incident patients, the percentage of patients receiving RRT at 90 days with a functioning transplant varied between centres from $0 \%$ to $31 \%$ (between $2 \%$ and $31 \%$ for transplanting centres and between $0 \%$ and $19 \%$ for non-transplanting centres). The mean percentage of the incident cohort with a functioning transplant at 90 days was greater in transplanting compared to non-transplanting centres $(12.1 \%$ vs $6.7 \%)$.

Table 1.12a. RRT modality at 90 days by country (incident cohort $1 / 10 / 2015$ to 30/09/2016)

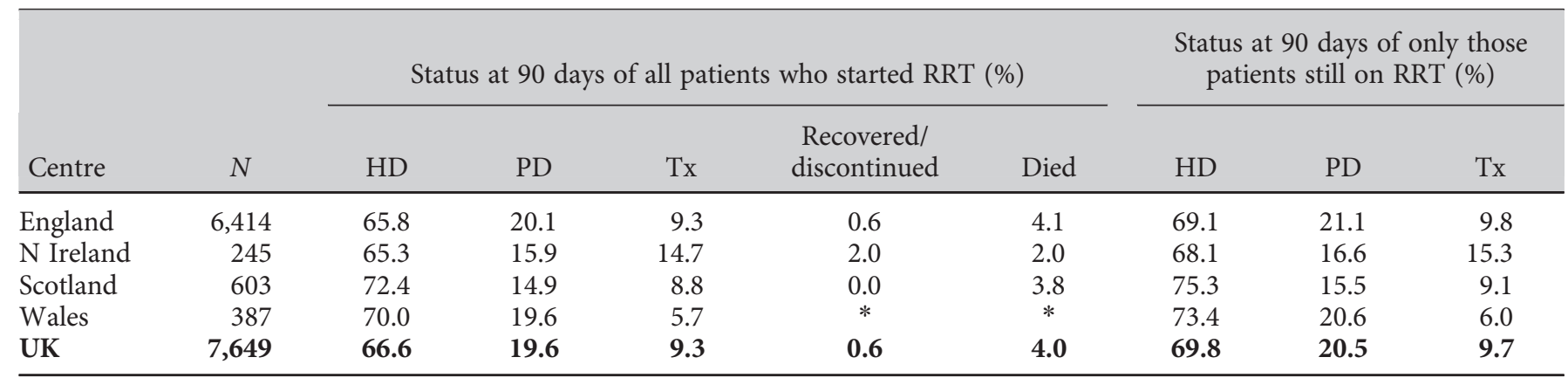

*Values suppressed due to small numbers (primary or secondary suppression) 
Table 1.12b. RRT modality at 90 days by centre (incident cohort $1 / 10 / 2011$ to $30 / 09 / 2016$ )

\begin{tabular}{|c|c|c|c|c|c|}
\hline Centre & $N$ & $\begin{array}{l}\text { Percentage } \\
\text { who had died } \\
\text { by } 90 \text { days }\end{array}$ & HD & PD & $\mathrm{Tx}$ \\
\hline B Heart & 560 & 5 & 74 & 23 & 3 \\
\hline B QEH & 1,147 & 2 & 73 & 18 & 9 \\
\hline Basldn & 218 & 4 & $*$ & 25 & $*$ \\
\hline Bristol & 765 & 5 & 71 & 18 & 11 \\
\hline Camb & 418 & 3 & 64 & 10 & 26 \\
\hline Carlis & 179 & $*$ & 54 & 40 & 6 \\
\hline Carsh & 1,237 & 6 & 74 & 20 & 7 \\
\hline Chelms & 244 & $*$ & $*$ & 20 & $*$ \\
\hline Dorset & 374 & 1 & 68 & 27 & 4 \\
\hline Dudley & 256 & 2 & $*$ & 34 & $*$ \\
\hline Exeter & 657 & 3 & 74 & 20 & 6 \\
\hline Glouc & 339 & 2 & 71 & 26 & 3 \\
\hline Hull & 492 & 4 & 60 & 32 & 8 \\
\hline Ipswi & 219 & 3 & 64 & 29 & 7 \\
\hline Kent & 676 & 5 & 72 & 18 & 11 \\
\hline L Barts & 1,459 & 4 & 64 & 29 & 7 \\
\hline L Guys & 763 & 2 & 73 & 10 & 17 \\
\hline L Kings & 764 & 2 & 71 & 25 & 4 \\
\hline L Rfree & 1,142 & 4 & 61 & 27 & 11 \\
\hline L St.G & 462 & 5 & 76 & 14 & 10 \\
\hline Newc & 551 & 6 & 69 & 20 & 10 \\
\hline Norwch & 437 & 5 & 79 & 18 & 4 \\
\hline Nottm & 560 & 5 & 55 & 30 & 15 \\
\hline Oxford & 913 & 4 & 59 & 23 & 17 \\
\hline Plymth & 280 & 6 & 64 & 22 & 14 \\
\hline Ports & 975 & 3 & 71 & 17 & 12 \\
\hline Prestn & 760 & 4 & 72 & 16 & 12 \\
\hline Redng & 486 & 5 & 60 & 32 & 8 \\
\hline Salford & 754 & 4 & 63 & 25 & 11 \\
\hline Sheff & 739 & 4 & 78 & 14 & 8 \\
\hline Shrew & 296 & 6 & 69 & 28 & 3 \\
\hline Stevng & 699 & 6 & 79 & 12 & 9 \\
\hline Sthend & 181 & 6 & 69 & 26 & 5 \\
\hline Stoke & 519 & 6 & 71 & 26 & 3 \\
\hline Sund & 335 & 2 & 83 & 11 & 6 \\
\hline Truro & 252 & 8 & 74 & 18 & 9 \\
\hline Wirral & 296 & 14 & 74 & 21 & 5 \\
\hline Wolve & 403 & 6 & 61 & 37 & 2 \\
\hline York & 293 & 3 & 62 & 24 & 14 \\
\hline
\end{tabular}


Table 1.12b. Continued

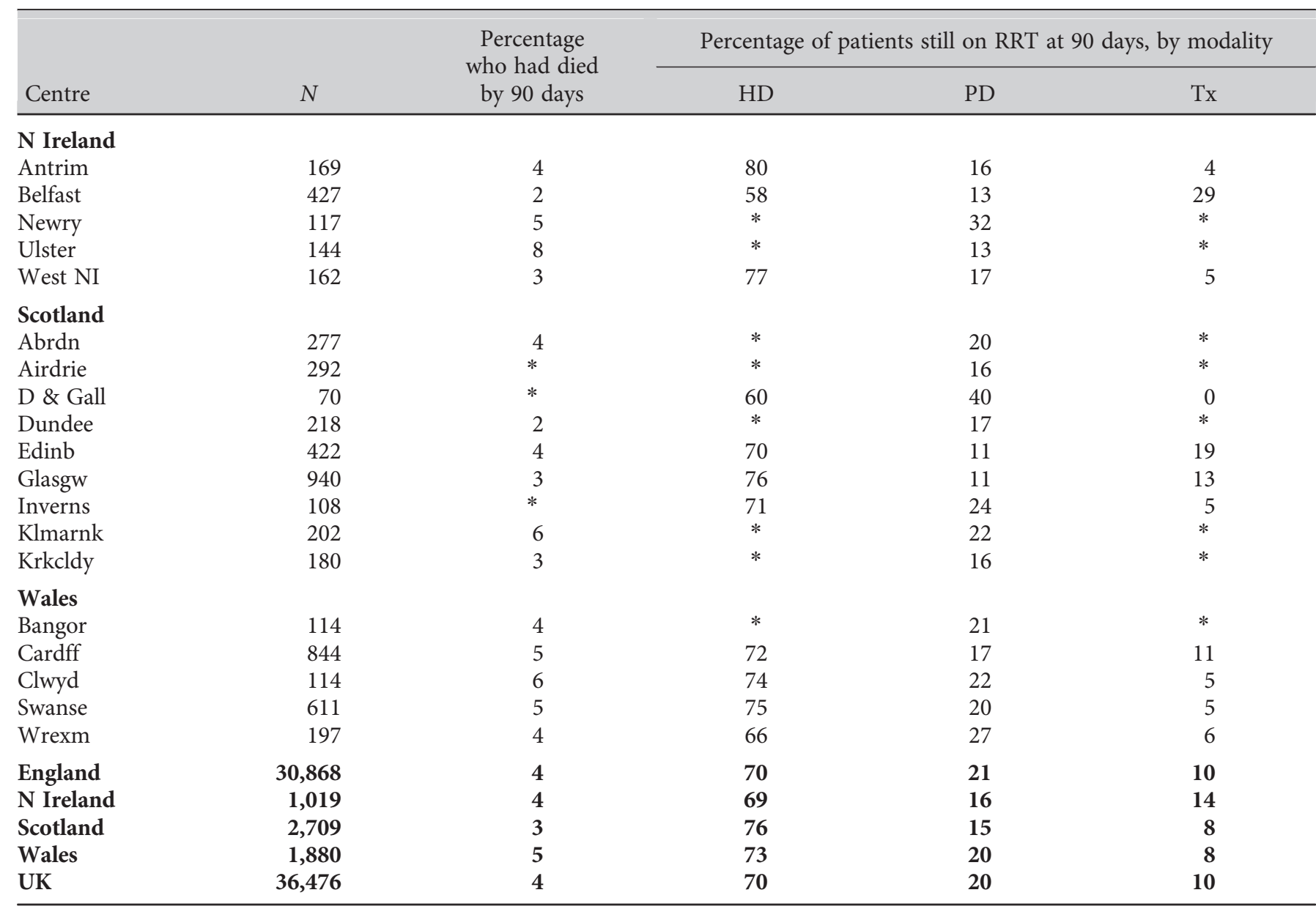

*Values suppressed due to small numbers (primary or secondary suppression)

Table 1.13 gives the HD/PD breakdown by age group for patients receiving dialysis at 90 days (incident cohort $1 / 10 / 2013$ to $30 / 09 / 2016$ ). The percentage on $\mathrm{PD}$ at

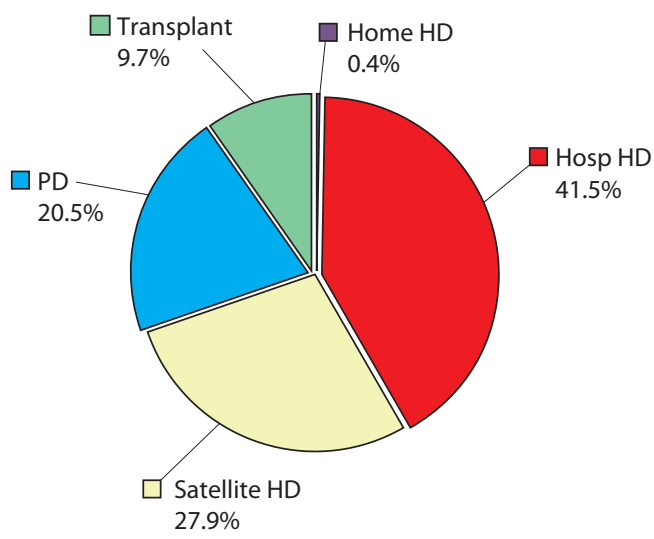

Fig. 1.9. RRT modality at 90 days (incident cohort $1 / 10 / 2015$ to 30/09/2016)

UK Renal Replacement Therapy Incidence in 2016
90 days was about $50 \%$ higher in patients aged under 65 years than in older patients (27\% vs $18 \%)$. In both age groups there was a lot of variability between centres in the percentage on PD. There were a small number of centres where the percentage of patients treated with $\mathrm{PD}$ was the same as, or higher in the over 65 s than the under $65 \mathrm{~s}$. Not all of these were centres with a high use of PD.

\section{Modality change over time}

Table 1.14 gives the breakdown of status/treatment modality at four subsequent time points by initial treatment type for patients starting RRT in 2011. Fifty-three percent of patients who started on HD had died within five years of starting. This compared to $35 \%$ and $5 \%$ for those starting on PD or transplant respectively. Of the patients starting on PD, 91\% were on PD at 90 days but this percentage dropped sharply at the later time

Nephron 2018;139(suppl1):13-46 
Table 1.13. Modality split of patients on dialysis at 90 days (incident cohort $1 / 10 / 2013$ to $30 / 09 / 2016$ )

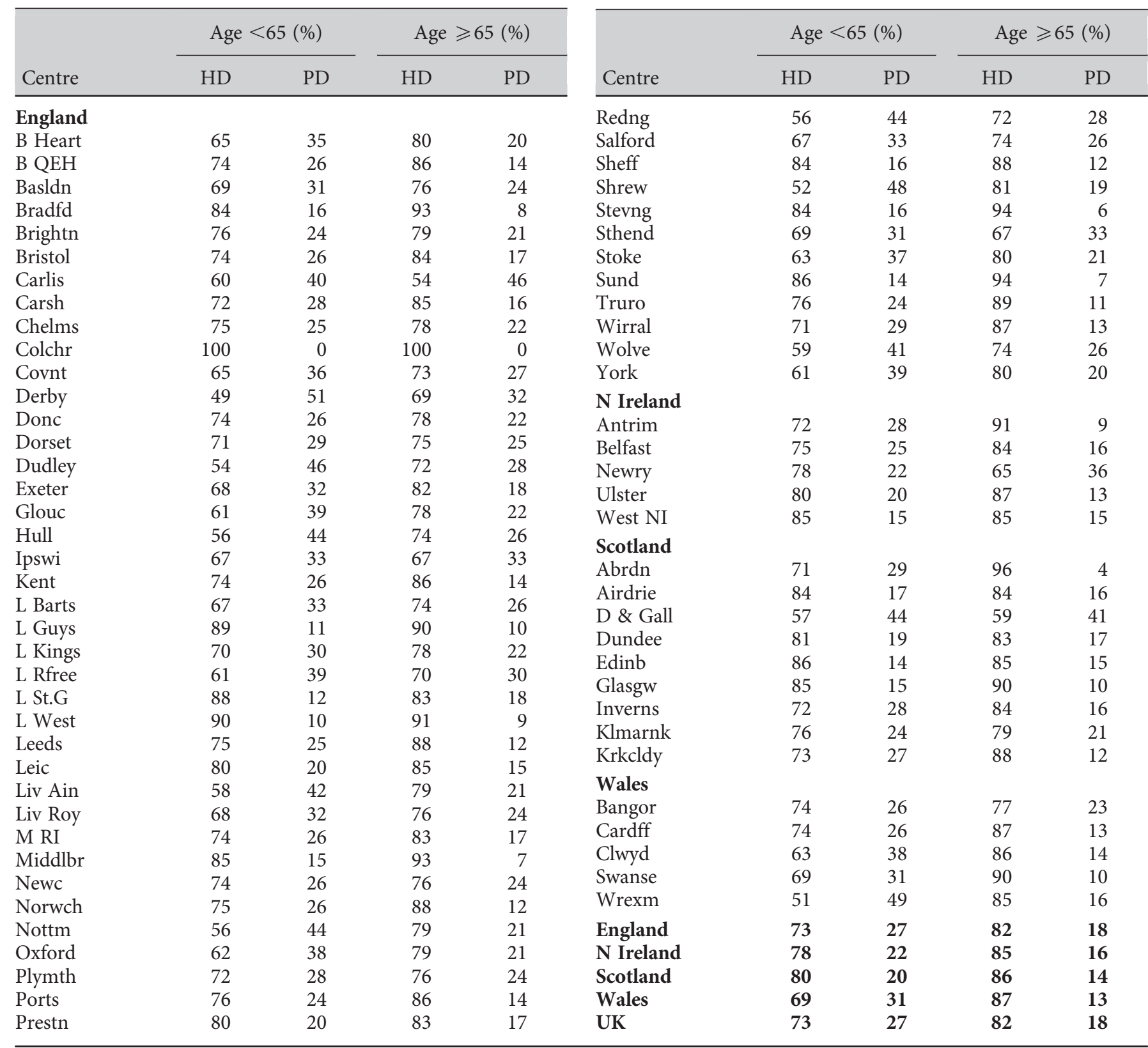

points. In contrast, $90 \%$ of patients starting with a transplant were also transplant patients at the five year time point.

\section{Renal function at the time of starting RRT}

The mean eGFR at initiation of RRT in 2016 was $7.4 \mathrm{ml} / \mathrm{min} / 1.73 \mathrm{~m}^{2}$. This was markedly lower than the $8.5 \mathrm{ml} / \mathrm{min} / 1.73 \mathrm{~m}^{2}$ reported last year. This difference is due to the use of the CKD-EPI rather than the MDRD formula. By the MDRD method the mean eGFR was
$8.5 \mathrm{ml} / \mathrm{min} / 1.73 \mathrm{~m}^{2}$ in 2016 . The mean eGFR at initiation of RRT is shown by age group in figure 1.10.

Figure 1.11 shows serial data from centres reporting to the UKRR every year since 2007. There has been a tendency for patients to start PD at higher eGFRs than HD recipients, seen again in 2016 (7.5 vs $7.1 \mathrm{ml} / \mathrm{min} /$ $1.73 \mathrm{~m}^{2}$ ).

Some caution should be applied to the analysis of eGFR at the start of RRT as data were only available for less than half of the incident patients (approximately 
Table 1.14. Initial and subsequent modalities for patients starting RRT in $2011^{*}$

\begin{tabular}{|c|c|c|c|c|c|c|}
\hline \multirow[b]{2}{*}{ First treatment } & \multirow[b]{2}{*}{$N$} & \multirow[b]{2}{*}{ Later modality } & \multicolumn{4}{|c|}{ Percentage } \\
\hline & & & 90 days & 1 year & 3 years & 5 years \\
\hline \multirow{3}{*}{$\mathrm{HD}$} & \multirow{3}{*}{4,864} & $\mathrm{PD}$ & 2 & 4 & 1 & 1 \\
\hline & & Transplant & 1 & 5 & 13 & 17 \\
\hline & & Recovered/discontinued & 0 & 1 & 2 & 1 \\
\hline \multirow[t]{5}{*}{$\mathrm{PD}$} & \multirow[t]{5}{*}{1,370} & $\mathrm{HD}$ & 6 & 15 & 20 & 17 \\
\hline & & $\mathrm{PD}$ & 91 & 67 & 28 & 10 \\
\hline & & Transplant & 1 & 10 & 30 & 37 \\
\hline & & Recovered/discontinued & 0 & 0 & 1 & 1 \\
\hline & & Died & 2 & 7 & 22 & 35 \\
\hline
\end{tabular}

* Cambridge excluded as five year follow up not available

Light grey shading indicates proportion of individuals maintained on their initial modality

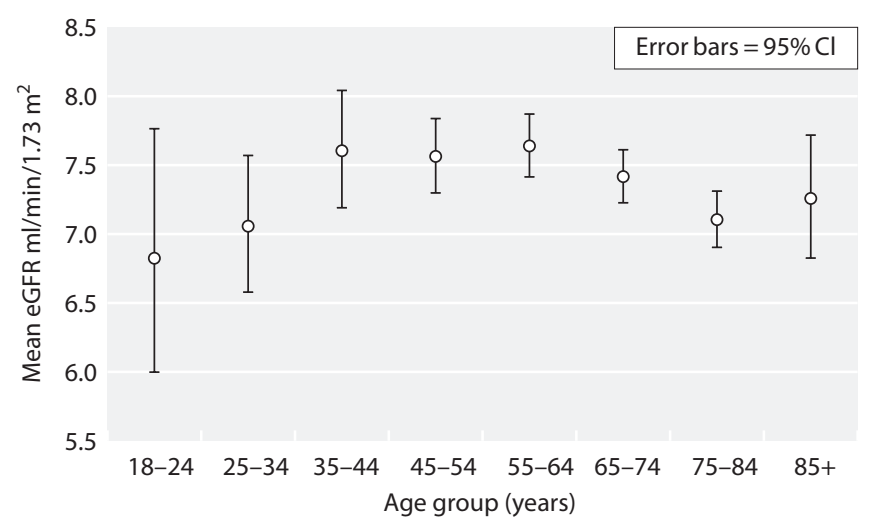

Fig. 1.10. Mean eGFR at start of RRT (2016) by age group Note, for this report the CKD-EPI method was used for the first time rather than the MDRD method

CKD-EPI estimated mean GFR at start approximately $1 \mathrm{ml} / \mathrm{min} / 1.73 \mathrm{~m}^{2}$ lower than MDRD

3,100 for 2016) and almost half of these came from only ten centres. Three-quarters of the values came from 20 centres. Further caution should be applied as some patients may have an incorrect date of starting RRT allocated and thus, the eGFR used for analysis may have been taken whilst they were already receiving RRT. This analysis is presented despite these deficiencies for comparision with historical data. Completeness of eGFR data and accuracy of start date are anticipated to improve with the introduction of realtime data downloads and more complete collection of HD sessional data.

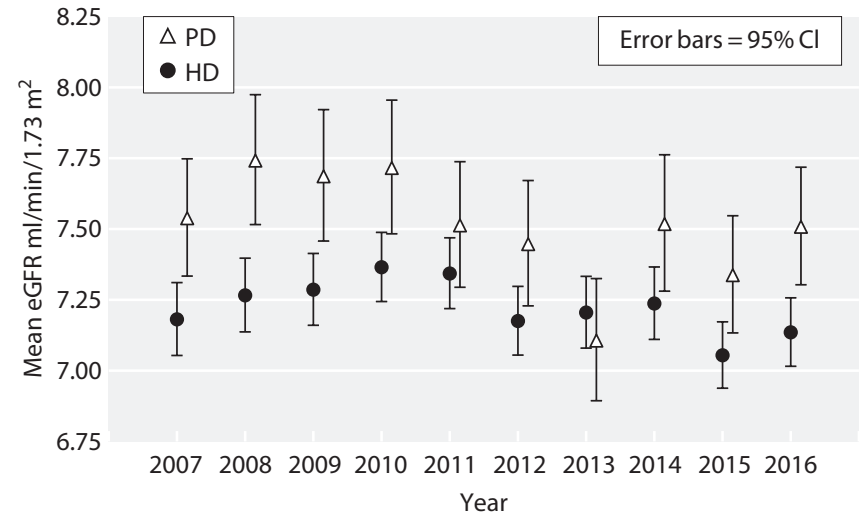

Fig. 1.11. eGFR on starting RRT 2007 to 2016, PD and HD (restricted to centres reporting since 2007)

Note, for this report the CKD-EPI method was used for the first time rather than the MDRD method

CKD-EPI estimated mean GFR at start approximately $1 \mathrm{ml} / \mathrm{min} / 1.73 \mathrm{~m}^{2}$ lower than MDRD

\section{Late presentation and delayed referral of incident patients}

\section{Introduction}

Late presentation to a nephrologist is regarded as a negative aspect in renal care. It can be defined in a number of ways as it has a range of possible causes. There are many patients with CKD who are regularly monitored in primary or secondary care and whose referral to nephrology services is delayed (delayed or 
late referral). Other patients present late to medical services with either such slowly progressive disease as to have remained asymptomatic for many years or with rapidly progressive kidney disease. The main analyses presented here do not differentiate between these groups and include any patient first seen by renal services within 90 days of starting RRT for ERF as 'late presentation'. One analysis attempts to capture 'late referrals': it shows the percentage presenting within 90 days of starting RRT after excluding conditions that are likely to present with rapid decline in renal function.

\section{Methods}

Date first seen by a nephrologist has not been collected from the Scottish Renal Registry and so Scottish centres were excluded from these analyses. Data were included for incident patients in English, Welsh or Northern Irish centres in the years 2015 to 2016. This two year cohort was used for most of the analyses in order to make the late presentation percentages more reliably estimated and to allow these to be shown for subgroups of patients. The date first seen in a renal centre and the date of starting RRT were used to define the late presenting cohort. A small amount of data was excluded because of actual or potential inconsistencies. Only data from those centres with $75 \%$ or more completeness for the relevant year were used. Data were excluded if more than $10 \%$ of patients were reported to have started RRT on the same date as the first presentation. This was because investigation has shown that this is likely due to misunderstanding on the part of the renal centres resulting in incorrect recording of data. After these exclusions, data on 10,966 patients were available for analysis. Presentation times of 90 days or more before start were defined as early presentation and times of less than 90 days were defined as late presentation.

Estimated glomerular filtration rate (eGFR) at the start of RRT was studied amongst patients with eGFR data within 14 days before the start of RRT. The eGFR was calculated using the CKD-EPI equation and the abbreviated 4 variable MDRD study equation to allow comparison with previously reported values. For the purpose of the eGFR calculation, patients who had missing ethnicity, but a valid serum creatinine measurement were classed as White. Due to their skewed distribution the eGFR values were $\log$ transformed.

A mixture of old and new (2012) EDTA codes for primary diagnoses were received from centres. For those people without an old code, new codes (where available) were mapped back to old codes. These codes were grouped into the same eight categories as in previous reports, the details are given in appendix $\mathrm{H}$ : Ethnicity and ERA-EDTA Coding (www.renalreg.org).

People with the following conditions were allocated to an 'acute' group in some analyses: crescentic (extracapillary) glomerulonephritis (type I, II, III), nephropathy (interstitial) due to cisplatinum, renal vascular disease due to malignant hypertension, renal vascular disease due to polyarteritis, Wegener's granulomatosis, cryoglobulinemic glomerulonephritis, myelomatosis/light chain deposit disease, Goodpasture's syndrome, systemic sclerosis (scleroderma), haemolytic ureaemic syndrome, multi-system disease - other, tubular necrosis (irreversible) or cortical necrosis, Balkan nephropathy, kidney tumour(s), and traumatic or surgical loss of kidney(s).

\section{Results}

\section{Data completeness}

Table 1.15 shows the percentage completeness of data for 2015 and 2016.

\section{Late presentation by centre}

Figure 1.12 shows that late presentation varied between centres from $5 \%$ to $34 \%$ in patients starting RRT in 2015 to 2016. The overall rate of late presentation was $15.9 \%$ and reduced to $11.2 \%$ once those people with diseases likely to present acutely were excluded. Table 1.16 shows the overall percentage presenting late for the combined 2015/2016 incident cohort, the percentages presenting late amongst those patients defined as

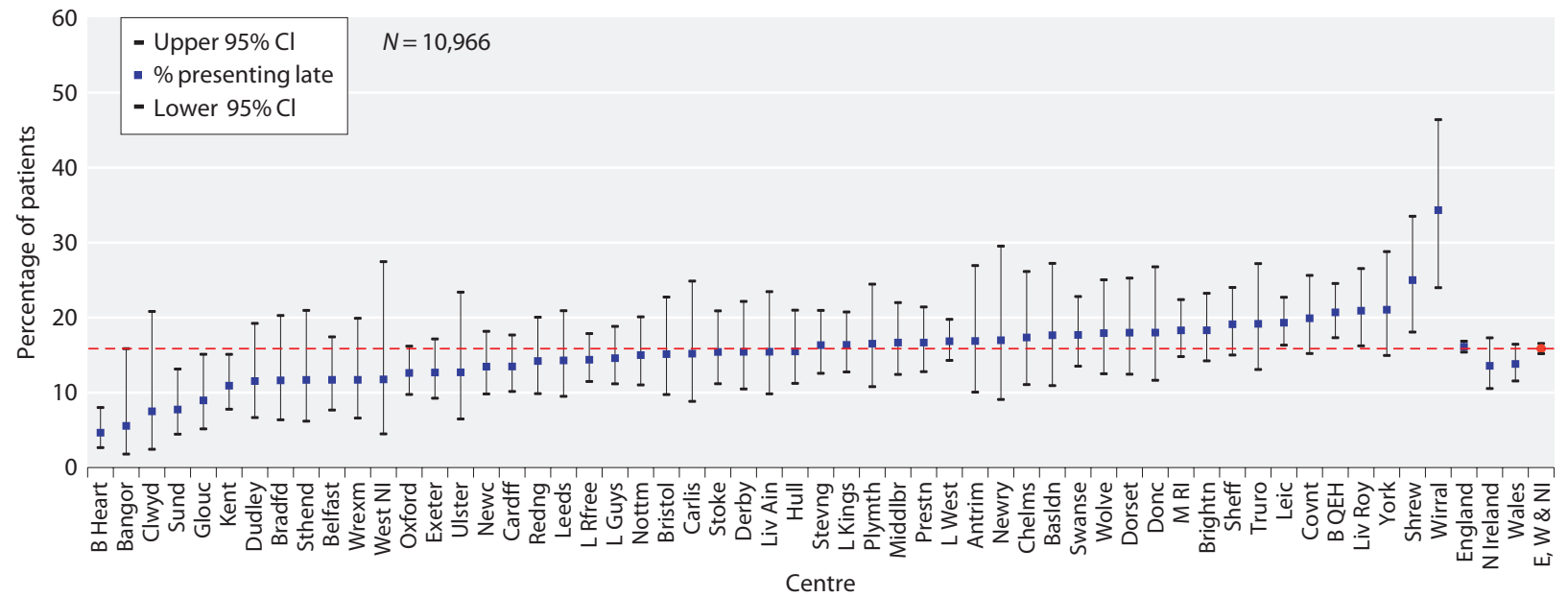

Fig. 1.12. Percentage presenting late (2015/2016) 
Table 1.15. Percentage completeness of time of presentation data (2015 and 2016 incident RRT patients) by centre

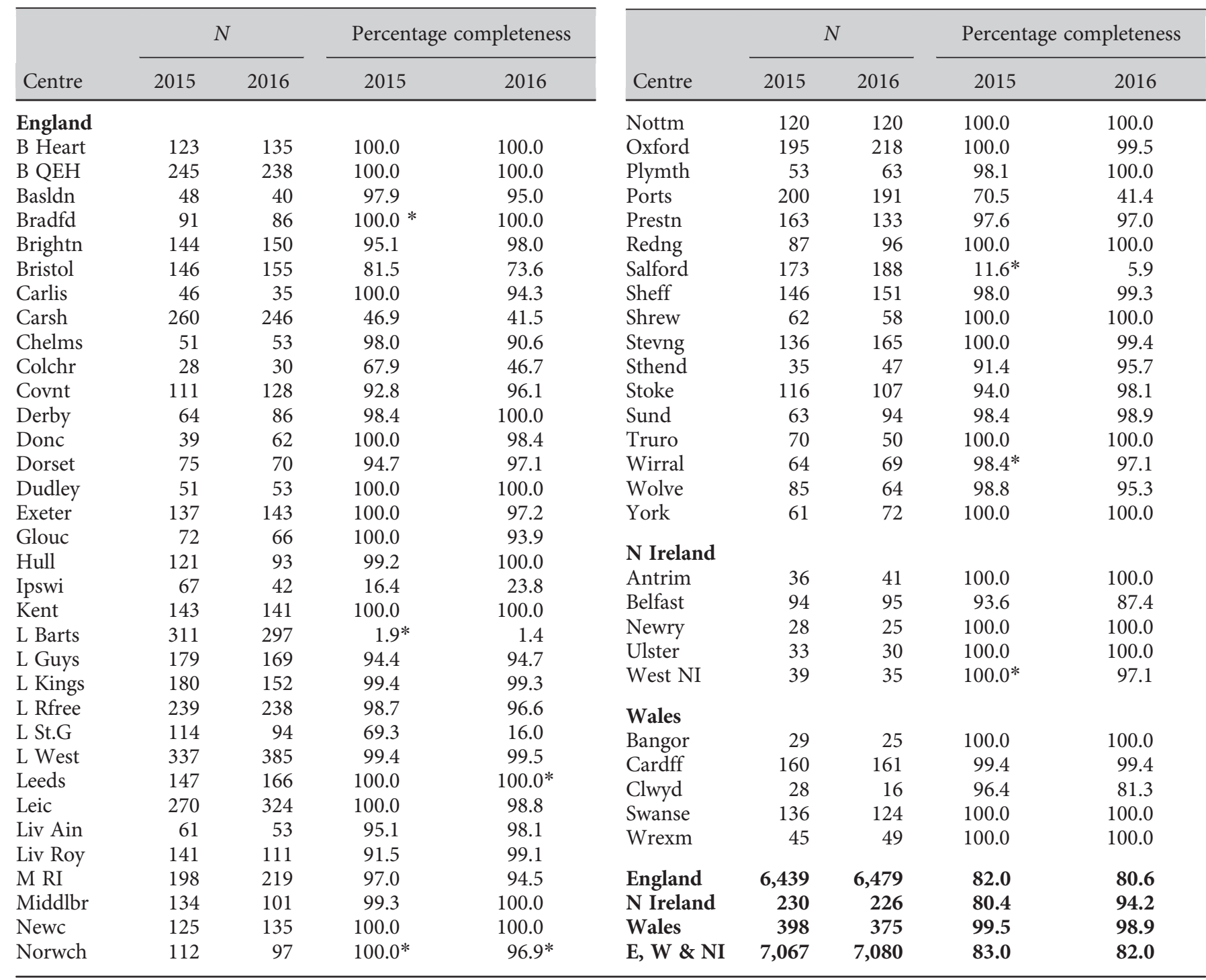

*Completeness data shown but data not used as $>10 \%$ of patients with data reported as starting RRT on same date as first presentation

not having an 'acute diagnosis' and the percentages amongst non-diabetics (as PRD).

Considerable differences exist between centres in late presentation rates. One centre (Birmingham Heartlands) attained a late presentation rate of just under 5\%. Two centres (Wirral, York) reported that over $40 \%$ of their incident patients were referred late. These differences have implications for their regions and referral pathways.

Late presentation in 2016 and the trend over time

There has been a steady decline nationally in the proportion of patients presenting late to renal services, with some centres achieving $<10 \%$ late presentation rates. In $2016,72.1 \%$ of incident patients presented to nephrology services over a year before they started RRT. The remaining patients presented within a year of start, with $7.8 \%$ of patients presenting within the 6-12 month window before RRT, $4.5 \%$ within 3-6 months and $15.6 \%$ within three months of RRT start. Figure 1.13 shows this breakdown by year for those 37 centres supplying data over $75 \%$ complete for each of the last six years. The figure shows an increase over time in the percentage of patients presenting a year or more before starting RRT. As shown in previous reports this increase was even more marked in the years before those shown in the figure. In 2005, 
Table 1.16. Percentage of patients presenting to a nephrologist less than 90 days before RRT initiation and percentage presenting less than a year before initiation (2015/2016 incident patients) by centre

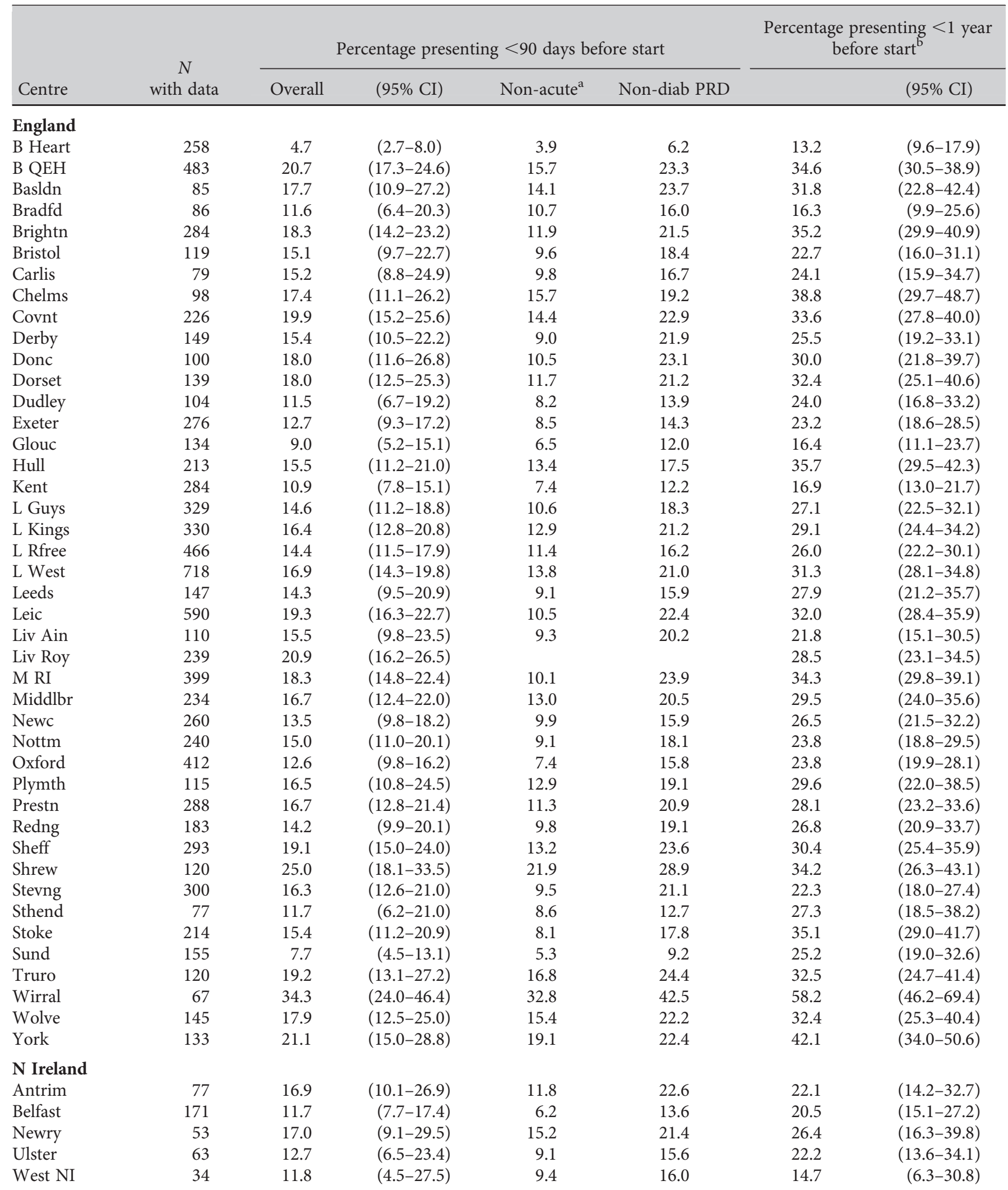


Table 1.16. Continued

\begin{tabular}{|c|c|c|c|c|c|c|c|}
\hline \multirow[b]{2}{*}{ Centre } & \multirow{2}{*}{$\begin{array}{c}N \\
\text { with data }\end{array}$} & \multicolumn{4}{|c|}{ Percentage presenting $<90$ days before start } & \multicolumn{2}{|c|}{$\begin{array}{c}\text { Percentage presenting }<1 \text { year } \\
\text { before start }\end{array}$} \\
\hline & & Overall & (95\% CI) & Non-acute ${ }^{a}$ & Non-diab PRD & & $(95 \% \mathrm{CI})$ \\
\hline \multicolumn{8}{|l|}{ Wales } \\
\hline Bangor & 54 & 5.6 & $(1.8-15.9)$ & 5.8 & 7.0 & 11.1 & $(5.1-22.6)$ \\
\hline Cardff & 319 & 13.5 & $(10.2-17.7)$ & 10.5 & 16.3 & 23.5 & $(19.2-28.5)$ \\
\hline Clwyd & 40 & 7.5 & $(2.4-20.8)$ & c & 0.0 & 10.0 & $(3.8-23.8)$ \\
\hline Swanse & 260 & 17.7 & $(13.5-22.8)$ & 12.1 & 23.2 & 28.9 & $(23.7-34.7)$ \\
\hline Wrexm & 94 & 11.7 & $(6.6-19.9)$ & 7.1 & 13.9 & 21.3 & $(14.2-30.7)$ \\
\hline England & 9,801 & 16.1 & $(15.4-16.9)$ & 11.4 & 19.3 & 28.7 & $(27.8-29.6)$ \\
\hline N Ireland & 398 & 13.6 & $(10.5-17.3)$ & 9.4 & 16.7 & 21.4 & $(17.6-25.7)$ \\
\hline Wales & 767 & 13.8 & $(11.6-16.5)$ & 10.2 & 17.0 & 23.5 & $(20.6-26.6)$ \\
\hline $\mathrm{E}, \mathrm{W} \& \mathrm{NI}$ & 10,966 & 15.9 & $(15.2-16.6)$ & 11.2 & 19.0 & 28.0 & $(27.2-28.9)$ \\
\hline Min & & $\cdots$ & & $\cdots$ & $\cdots$ & $\cdots$ & \\
\hline $\begin{array}{l}\text { Minn } \\
\text { Quartile 1 }\end{array}$ & & $\begin{array}{r}4.7 \\
12.7\end{array}$ & & $\begin{array}{l}3.9 \\
9.0\end{array}$ & $\begin{array}{r}0.0 \\
15.9\end{array}$ & $\begin{array}{l}10.0 \\
22.7\end{array}$ & \\
\hline Quartile 3 & & 17.9 & & 13.1 & 22.3 & 32.0 & \\
\hline $\operatorname{Max}$ & & 34.3 & & 32.8 & 42.5 & 58.2 & \\
\hline
\end{tabular}

Blank cells - data for PRD not used due to high \% with missing data or high \% with uncertain aetiology

${ }^{a}$ Non-acute group excludes those diagnoses defined as acute (see methods)

${ }^{\mathrm{b}}$ The remaining patients starting RRT therefore presented over 1 year beforehand

${ }^{c}$ Value suppressed due to small numbers

only $52.6 \%$ of incident patients presented over a year before they started RRT.

\section{Characteristics of patients presenting late versus those} presenting early

In the combined 2015/2016 incident cohort, the median age was a little lower in those presenting late than those presenting early (table 1.17). The percentage who were male was higher in the group presenting late than those presenting early. There were large differences in the percentages starting on PD and in haemoglobin and eGFR at start with all three of these being lower in

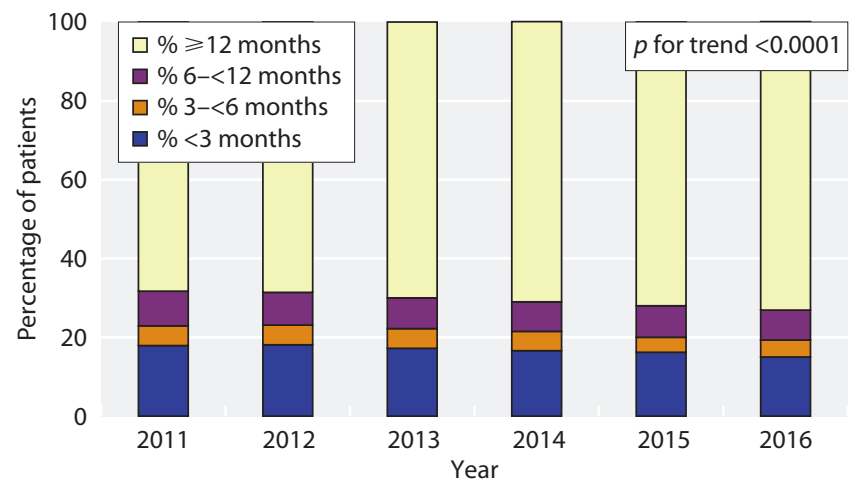

Fig. 1.13. Late presentation rate by year (2011-2016) Restricted to centres reporting continuous data for 2011-2016 late presenters than in early presenters. More detailed analyses of haemoglobin at start of RRT and late presentation can be found in chapter 7: Haemoglobin, Ferritin and Erythropoietin in UK Adult Dialysis Patients in 2016. The finding of lower average eGFR in those presenting late is in contrast to some of the studies in the literature but many of those studies pre-date the era of routine use of eGFR [5, 6]. A Cochrane review [7] showed that eGFR was lower in RRT patients referred

Table 1.17. Patient characteristics amongst patients presenting late ( $<90$ days) compared with those presenting early $(\geqslant 90$ days) (2015/2016 incident patients)

\begin{tabular}{lccc}
\hline & $<90$ days & $\geqslant 90$ days & $p$-value \\
\hline Median age & 63.8 & 64.9 & 0.01 \\
Percentage male & 65.8 & 62.3 & 0.01 \\
Percentage starting on PD & 9.7 & 22.4 & $>0.0001$ \\
Percentage on PD at 90 days & 12.0 & 22.2 & $>0.0001$ \\
$\begin{array}{l}\text { Mean haemoglobin at RRT } \\
\quad \text { start }(\mathrm{g} / \mathrm{L})^{\mathrm{a}}\end{array}$ & 91 & 100 & $>0.0001$ \\
$\begin{array}{l}\text { Mean eGFR at RRT start } \\
\quad\left(\mathrm{ml} / \mathrm{min} / 1.73 \mathrm{~m}^{2}\right)^{\text {ab }}\end{array}$ & 6.7 & 7.5 & $>0.0001$ \\
\hline
\end{tabular}

${ }^{a}$ Data only available for about $50 \%$ of patients

${ }^{b}$ Note, for this report the CKD-EPI method was used for the first time rather than the MDRD method

CKD-EPI estimated mean GFR at start approximately $1 \mathrm{ml} / \mathrm{min} /$ $1.73 \mathrm{~m}^{2}$ lower than MDRD 


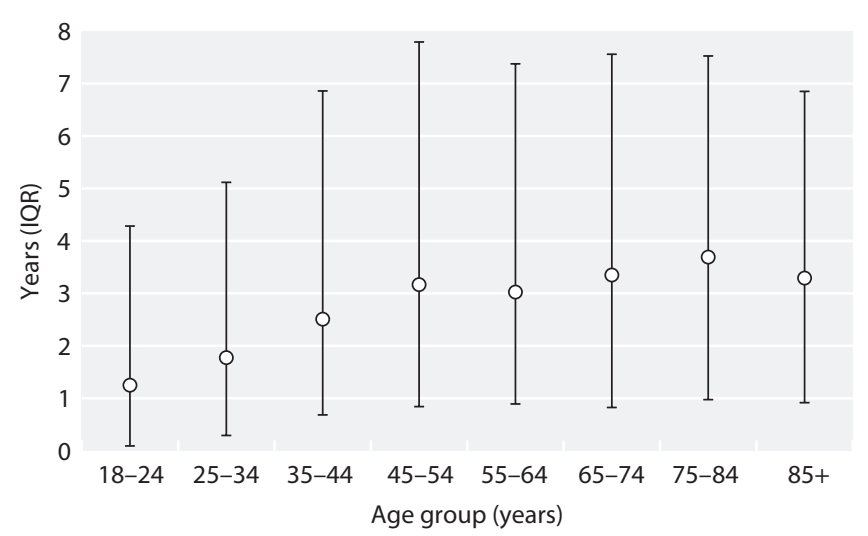

Fig. 1.14. Median duration of pre-RRT care by age group (incident patients 2015/2016)

late (mean difference of $0.42 \mathrm{ml} / \mathrm{min} / 1.73 \mathrm{~m}^{2}$ ) compared to those presenting early (definition: more than six months before starting RRT) consistent with UKRR data.

In the 2015/2016 cohort, the percentage of non-White patients presenting late ( $<90$ days) was lower than in Whites (13.8\% vs $16.3 \%$ : $p=0.005)$. The high incidence of diabetes in non-Whites (patients with diabetes tended to present earlier) explains some of the difference in presentation time between the groups. When patients with diabetes were excluded, the percentages presenting late $(<90$ days $)$ became $18.3 \%$ in non-White patients vs $19.5 \%$ in Whites $(p=0.3)$. Above age 45 , the median duration of pre-RRT care did not vary greatly with age group (figure 1.14).

\section{Primary renal disease and late presentation}

In the 2015/2016 cohort, there were large differences in late presentation rates between PRDs (Chi-squared test $p<0.0001$ ) (table 1.18). Patients with conditions likely to present with rapid decline in renal function or without available data had high rates of late presentation, as anticipated. Those with diabetes and adult polycystic kidney disease or pyelonephritis had low rates, in keeping with the natural histories of these conditions.

\section{Comorbidity and late presentation}

In the 2015/2016 cohort, the percentage of patients with no recorded comorbidity was similar amongst early and late presenters (50.2\% vs $51.8 \%$ : $p=0.4$ ). However, cardiovascular disease was less common and liver disease and malignancy more common in patients who presented late, compared with those who presented early (table 1.19). This is in keeping with findings from other studies $[5-6,8]$.

\section{International comparisons}

Figure 1.15 shows the crude RRT incidence rates (including children) for 2015 for various countries. The non-UK data are from the USRDS [9]; 2015 was the latest year available at the time of writing. The UK incidence rate was comparable with other Northern European countries, Australia and New Zealand, but remained markedly lower than other countries, most notably Greece, Japan and the USA. There are numerous reasons for these differences which have been documented and explored in other ecological studies and summarised by this review [10].

\section{Survival of incident patients}

See chapter 5: Survival and Causes of Death of UK Adult Patients on Renal Replacement Therapy in 2016.

Table 1.18. Late presentation by primary renal diagnosis (2015/2016 incident patients)

\begin{tabular}{lrrr}
\hline & & \multicolumn{2}{c}{ Late presentation } \\
\cline { 3 - 4 } Diagnosis & $N$ & $N$ & $\%$ \\
\hline Uncertain aetiology & 1,514 & 273 & 18.0 \\
Diabetes & 2,811 & 194 & 6.9 \\
Glomerulonephritis & 1,390 & 184 & 13.2 \\
Other identified category & 921 & 163 & 17.7 \\
Polycystic kidney or & 1,353 & 100 & 7.4 \\
$\quad$ pyelonephritis & & & \\
Renal vascular disease & 1,227 & 121 & 9.9 \\
Acute group & 968 & 524 & 54.1 \\
Data not available & 361 & 105 & 29.1 \\
\hline
\end{tabular}

Unlike elsewhere in the report: (i) the RVD group includes hypertension, and (ii) polycystic kidney and pyelonephritis are grouped together

For definition of acute group see methods

Table 1.19. Percentage prevalence of specific comorbidities amongst patients presenting late $(<90$ days) compared with those presenting early ( $\geqslant 90$ days) $(2015 / 2016$ incident patients)

\begin{tabular}{lccc}
\hline Comorbidity & $<90$ days & $\geqslant 90$ days & $p$-value \\
\hline Ischaemic heart disease & 13.0 & 20.6 & $<0.0001$ \\
Cerebrovascular disease & 5.9 & 10.4 & $<0.0001$ \\
Peripheral vascular disease & 8.3 & 11.5 & 0.003 \\
Diabetes (not a cause of ERF) & 10.6 & 10.7 & 0.9 \\
Liver disease & 5.6 & 3.4 & 0.001 \\
Malignancy & 19.3 & 12.4 & $<0.0001$ \\
COPD & 8.4 & 7.9 & 0.6 \\
Smoking & 10.7 & 13.0 & 0.05 \\
\hline
\end{tabular}




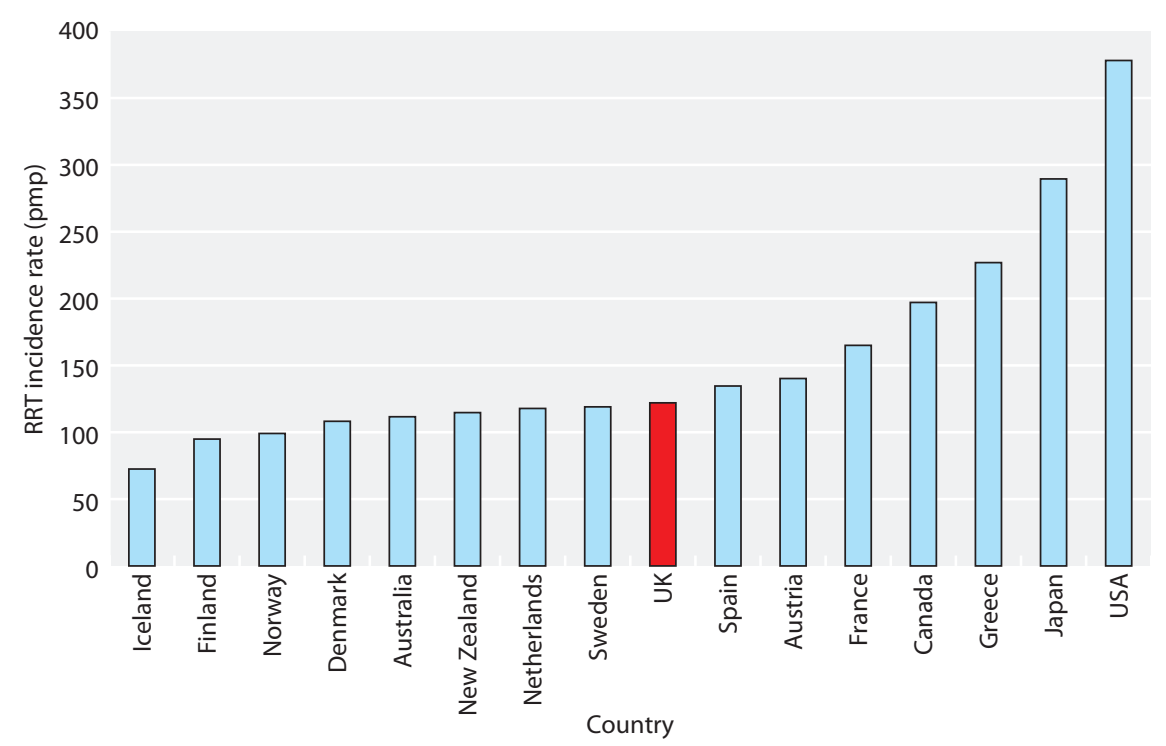

Fig. 1.15. International comparison of RRT incidence rates in 2015 Non-UK data from USRDS [9]

\section{Acute haemodialysis}

\section{Methods}

This section utilises sessional HD data alongside treatment timeline codes. HD sessional data were submitted to the UKRR by renal centres in England, as mandated by NHS England. Centres in Northern Ireland and Wales provided data voluntarily. Centres in Scotland did not provide HD sessional data. Centres were asked to report details related to each HD session, including vascular access used and blood pressure before and after the session (data not shown).

The approach used to define $\mathrm{HD}$ as acute or for ERF was based purely on timeline codes (figure 1.16). Sessional HD data were used to check for individuals who received HD without a timeline entry and to check start dates. Where timeline and sessional dates were inconsistent, it was not possible to determine whether this was due to a missing acute $\mathrm{HD}$ code or an inaccurate first timeline entry. As such, neither the dates nor content of timelines were corrected using sessional HD data.

\section{Results}

Timeline data from 2016 show 6,891 people received their first-ever HD session across 61 centres in England, Wales and Northern Ireland. Of these HD starts, 2,581 (37.5\%) were coded as acute and 4,310 (62.5\%) as being for ERF (figure 1.16).

Forty-one of the $52(78.8 \%)$ adult renal centres in England submitted HD sessional data. Of these, four submitted only acute HD sessions and one submitted data for only $16.8 \%$ of patients. Five centres in Northern Ireland and five in Wales also submitted data, of which two centres did not submit acute HD sessions. A table of completeness of the HD sessional data is available in appendix F: Additional Data Tables for 2016 new and existing patients.

Of the 2,581 individuals who started acute HD, sessional data were available for 2,332 (90.4\%). Fifty-three

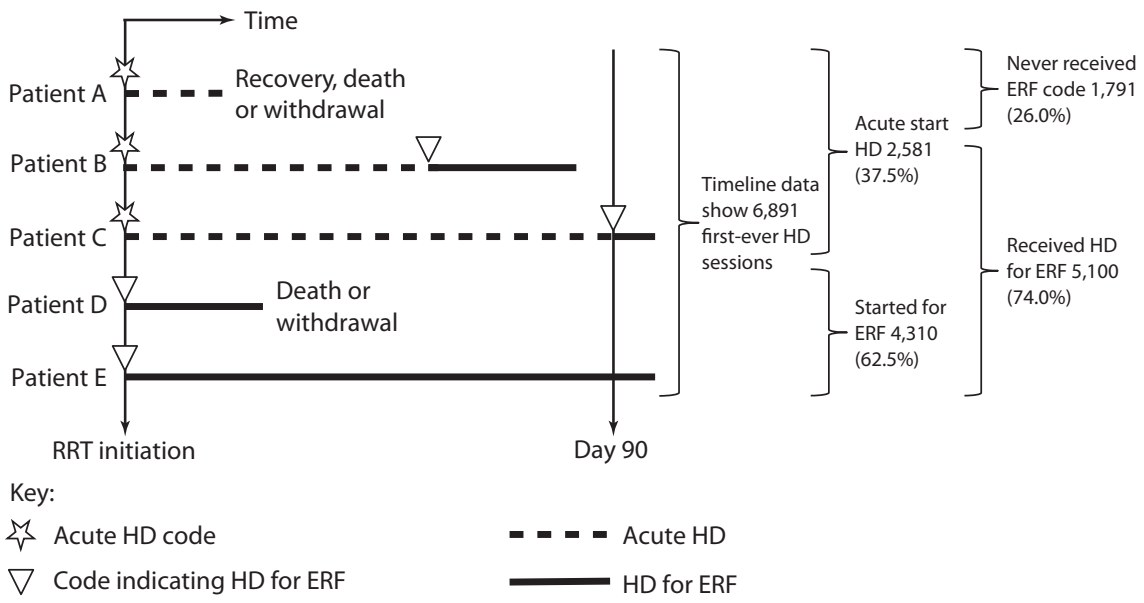

Fig. 1.16. Timeline codes and renal outcomes for all 6,891 people who received their first-ever HD session in England, Northern Ireland and Wales in 2016 
Table 1.20. Centre-level acute and chronic haemodialysis initiation

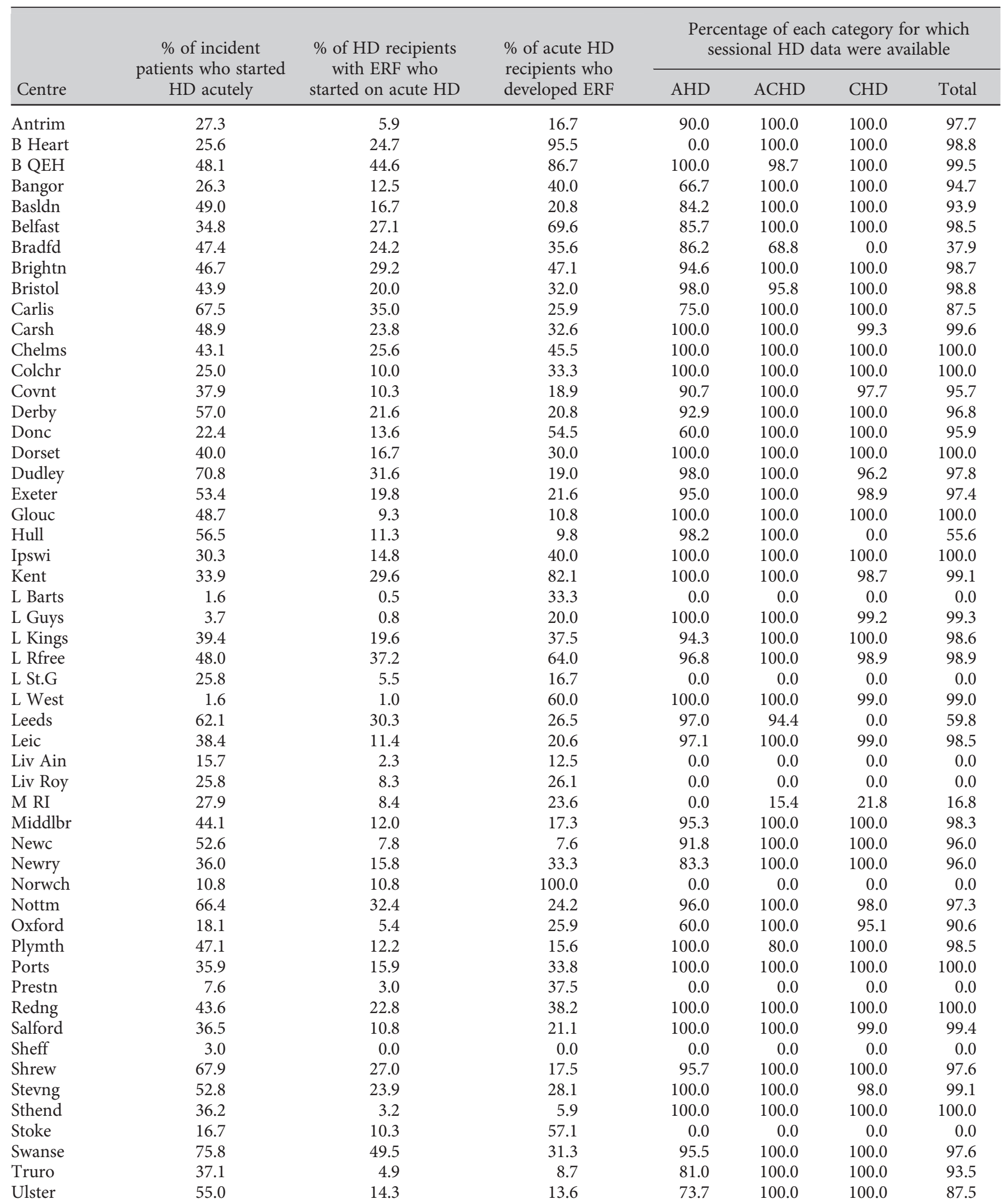


Table 1.20. Continued

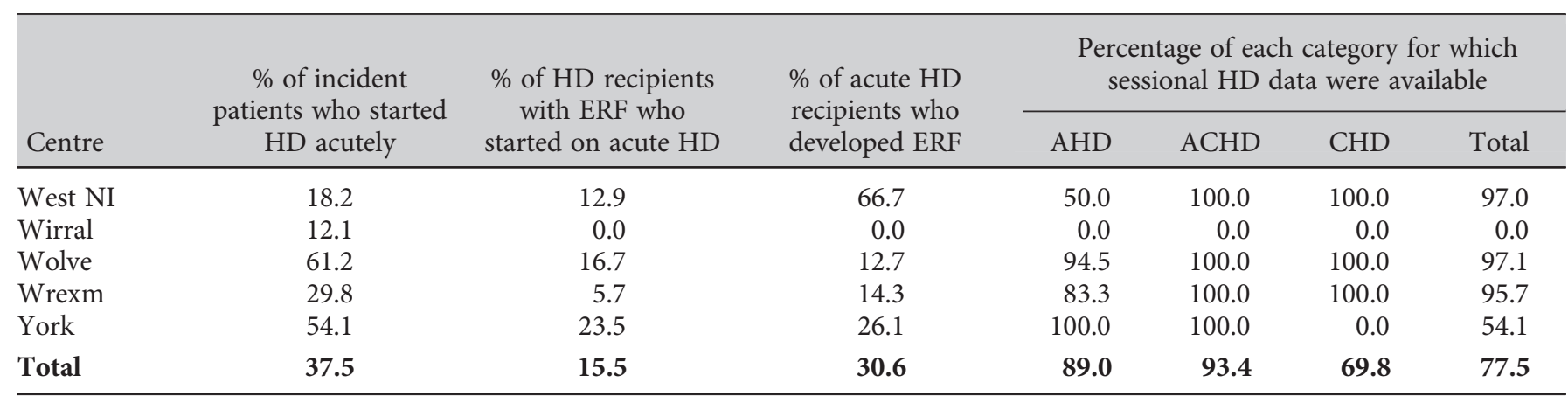

Ten centres supplied no HD sessional data and four supplied acute sessional data only. Three centres do not use acute timeline codes and are not included in this table

HD - haemodialysis; ERF - established renal failure; AHD - started acute HD but never coded as ERF; ACHD - started acute HD and recoded as ERF; CHD - started HD with ERF

acute HD recipients (2.3\%) had one or more HD sessions preceding their timeline date of dialysis initiation. A further $47(2.0 \%)$ had sessional data available by at least two weeks after the date of reaching ERF.

Of the 4,310 individuals who started HD for ERF, sessional data were available for 3,010 (69.8\%). One hundred and forty-five individuals starting HD for ERF (4.8\%) had one or more HD sessions preceding the timeline date of dialysis initiation. Only seven individuals were identified who had sessional HD data, but no timeline entry for acute or chronic HD. These seven individuals were excluded from all analyses. It is not possible to further quantify how many individuals received RRT in 2016 without a timeline code to indicate this.

Acute and chronic HD starts and progression to ERF

Of the 6,891 people who received their first-ever HD session in England, Northern Ireland and Wales in 2016, 5,100 (74.0\%) received an ERF code. Of these, 4,310 (84.5\%) started HD for ERF, whilst 790 (15.5\%) started HD acutely and were subsequently recoded as having ERF. HD sessional data were available for 3,748 (73.5\%). A further 1,791 individuals (26.0\%) commenced acute HD, but did not develop ERF. Sessional data were available for $1,594(89.0 \%)$ of these individuals. Data relating to death and recovery will be presented in a future report.

Excluding centres that contributed very incomplete or no HD sessional data, 4,191 (79.7\%) of 5,257 timeline and sessional HD start dates were identical and $97.2 \%$ were within two weeks of each other. Only $31(0.6 \%)$ of the timeline start dates were preceded by two or more weeks of HD sessions.

UK Renal Replacement Therapy Incidence in 2016
Table 1.20 presents data for all HD starters at centre level. There was large variation in acute HD use reported by centres, with the percentage of HD starters who received acute $\mathrm{HD}$ ranging between $1.6 \%$ and $75.8 \%$. The proportion of patients who developed ERF after starting acute HD ranged between $0.0 \%$ and $49.5 \%$.

\section{Demography and clinical details of individuals who} received only acute $H D$

Table 1.21 presents demographic and clinical data for the 1,791 individuals who commenced acute HD, but did not progress to ERF. Overall, $62.5 \%$ were male and the median age was 70.1 years. Forty-six percent had no cause for AKI coded and a further $16.9 \%$ had the cause of their AKI coded non-specifically as 'acute kidney injury'. Seventy-one percent were white and $6.1 \%$ were of minority ethnic background. Centres are anonymised in table 1.21 due to the small numbers of patients in some sub-categories and the potential risk of identification.

\section{Discussion}

The UK RRT incidence rate for 2016 was 118 pmp, reflecting RRT initiation for 7,759 new patients with ERF. This rate was lower than in 2015 (120 pmp), with significantly lower incidence in Scotland compared with England. Diabetic renal disease remained the single most common cause of renal failure treated by RRT (28.6\%), despite late presentation with this condition being the lowest of all PRDs. More men than women

Nephron 2018;139(suppl1):13-46 
Table 1.21. Demographic and clinical data for individuals who commenced acute haemodialysis, sorted by number of patients

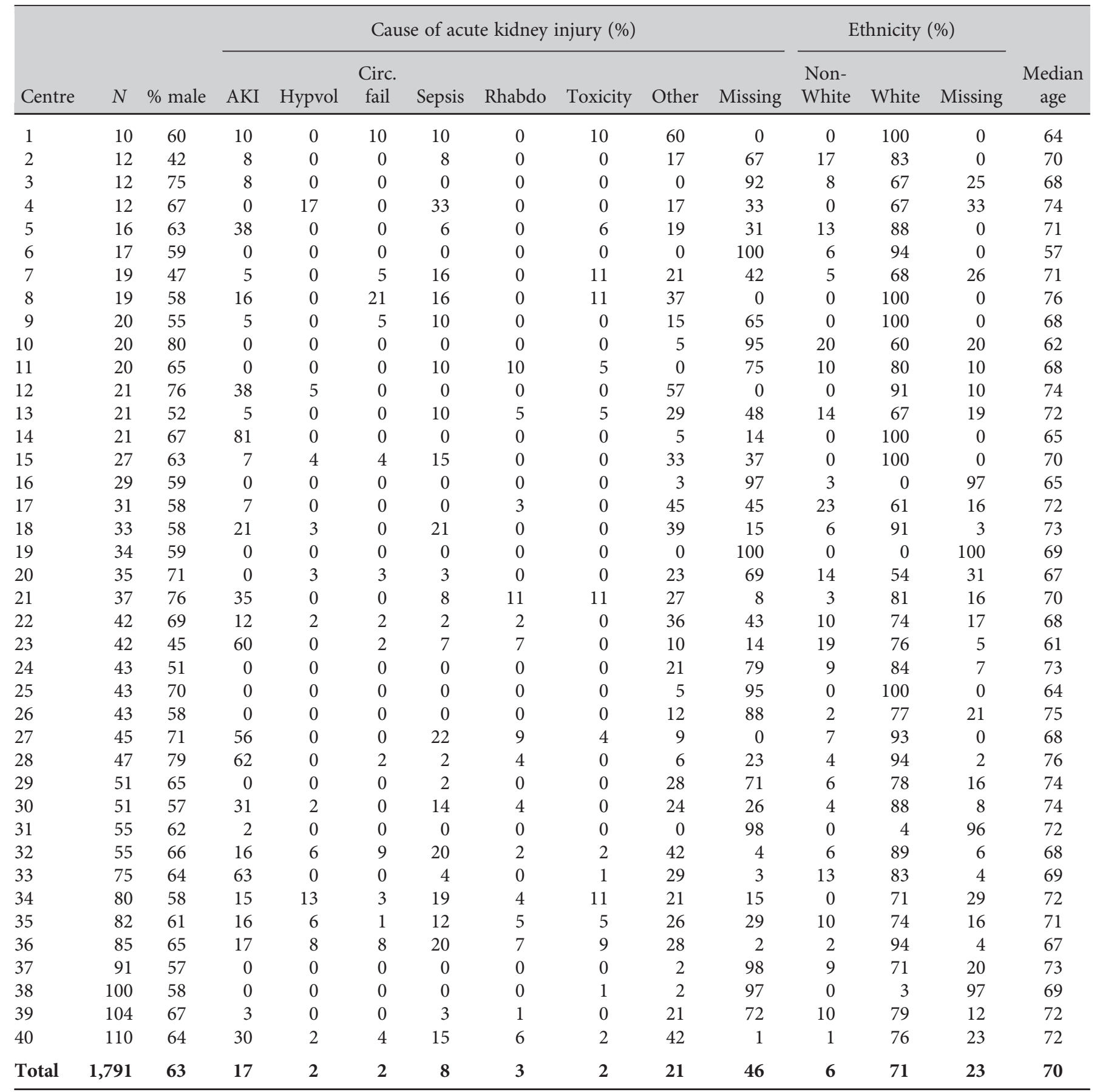

Centres where $N<10$ are not shown and centres are anonymised due do the small numbers of patients in some sub-categories and the potential risk of identification

$N$ - number of individuals starting acute haemodialysis at centre; Hypvol. - hypovolaemia; Circ. fail - circulatory failure; Rhabdo.- rhabdomyolysis; Toxicity - nephrotoxicity; AKI - acute kidney injury

The category 'Other' for cause of AKI, groups all of the following answers: pyelonephritis, diabetic kidney disease, renovascular disease, glomerulonephritis, hypertension, uncertain or 'other' 
started RRT in every age group (overall $62.9 \%$ male, $37.1 \%$ female). Incidence amongst the over-65s, which more than tripled between 1990 and 2005, appears to have plateaued at approximately $320 \mathrm{pmp}$ for the past decade. Incidence amongst those aged under 45 has also been stable. Meanwhile, incidence amongst 45 to 64-year olds continued to rise, albeit marginally between 2015 and 2016.

Whilst overall incidence has stabilised, both incidence rates and the total number of new starters was highest in older people. With ongoing population growth and ageing, the incident RRT population is likely to expand and age over the coming decades. The median age of all incident patients in 2016 was 64.3 years, but this was highly dependent on ethnicity (66.2 years for White incident patients; 58.7 years for non-White patients). There was marked variation between CCG/HBs in the rates of older people $(>75)$ starting RRT. This may signify true practice variation, reflective of uncertainty within the renal community about the benefits of dialysis for the oldest patients. However, these data are not adjusted for factors such as rates of comorbid illness or ethnicity that differ between CCG/HBs, or the life-expectancy of the general population, which varies across the UK. A proportion of individuals who developed ERF received comprehensive conservative care in place of renal replacement therapy. Inclusion of CKD data will allow estimation of this population in the near future and will enhance the interpretation of RRT incidence rates.

The percentage of RRT patients at 90 days who had a functioning transplant varied between centres from $0 \%$ to
$31 \%$ (between $2 \%$ and $31 \%$ for transplanting centres and between $0 \%$ and $19 \%$ for non-transplanting centres). These data might be seen to represent that transplantation was more likely for an individual who was primarily looked after at a transplant centre. An alternative explanation is that some patients transplanted preemptively were attributed to the incident cohort of their transplanting centre, rather than that from which they were referred.

Although large numbers of patients continued to present late to renal centres, this proportion has dropped substantially in the last decade, from $23.9 \%$ in 2006 to $15.6 \%$ in 2016 . This may be a consequence of CKD guidelines published by NICE [11], the Quality and Outcomes Framework (QOF) initiative (www.dh.gov.uk) raising awareness of CKD amongst non-nephrologists and the introduction of estimated GFR reporting. Late presentation continued to fall and some centres reported rates of $<10 \%$. The proportion of late presenting individuals who have acute or undetected disease is unknown. Correspondingly, the amount of truly avoidable late presentation is unquantified. The Health Foundation has funded an initiative that flags people with declining kidney function to their GP, to ensure they have considered referral to a nephrologist (ASSIST-CKD [12]). This initiative is being managed through Kidney Research UK and the UKRR is leading the evaluation to establish effectiveness.

In 2016, 1,791 individuals in England, Northern Ireland and Wales commenced acute $\mathrm{HD}$, but did not develop ERF. These individuals made up $26 \%$ of those

Table 1.22. Instructions for reporting centres regarding use of timeline codes to indicate dialysis initiation

1) Coding must be consistent between centres

2) The timeline should be used to record the date of first dialysis or haemofiltration:

Acute dialysis codes:

81 Acute HD

82 Acute haemofiltration

83 Acute PD

\author{
Example dialysis codes indicating ERF (not an exhaustive list)* \\ 1 HD \\ 3 Haemodiafiltration \\ 11 CAPD \\ 12 APD
}

3) For those who start with an acute code, a separate code must subsequently indicate:

ARF recovered - code 84

ARF stopped dialysis (without recovery of function) - code 85

Development of ERF (codes as listed above plus transplantation)

This code must not be backdated

*For a full list of treatment modality codes see: https://www.renalreg.org/datasets/the-uk-renal-registry-dataset/

CAPD - continuous ambulatory peritoneal dialysis; APD - automated peritoneal dialysis; ARF - acute renal failure 
who received HD for the first time during this period. This summary statistic masks striking variation in the reported use of and outcomes from acute HD between centres. Clinical explanations for variation include case mix, case selection and thresholds for initiating dialysis, and the proportion of individuals treated with acute PD or haemofiltration in intensive care units. It seems likely, however, that inconsistent use of timeline codes contributes substantially to inter-centre variation.

Whether an individual is receiving dialysis for AKI or ERF leaves considerable room for clinical interpretation, especially amongst those with advanced CKD. It may be that even a uniform approach to timeline coding cannot adequately distinguish between these groups. Significant input from all contributing renal centres is necessary to ensure data of adequate quality are returned to permit accurate and meaningful conclusions. Since 2009, the UKRR has asked clinicians to use the timeline field on their renal IT system to record the date of first dialysis or haemofiltration and separately, the date on which the patient was deemed to have reached ERF. This allows the distinction between patients who have an acute start and those whose start on RRT was planned. If the patient recovers renal function, an entry should be made in the timeline (table 1.22). Centres should not backdate ERF codes to the date of dialysis initiation, as this negatively influences the quality of survival analyses.

Reassuringly, sessional HD data suggested that start dates are precise for $79.7 \%$ and within two weeks for 97.2\% of incident HD recipients. These low levels of discordance are unlikely to meaningfully influence overall survival analyses for all HD recipients, although the effect on other analyses (such as eGFR at start) may be greater. The UKRR hopes to improve such analyses with the introduction of realtime data downloads for individuals with advanced CKD and more complete collection of HD sessional data.

\section{Acknowledgement}

The (non-UK) data reported in the section on International comparisons have been supplied by the United States Renal Data System (USRDS). The interpretation and reporting of these data are the responsibility of the author(s) and in no way should be seen as an official policy or interpretation of the U.S. government.

Conflicts of interest: the authors declare no conflicts of interest

\section{References}

1 https://renal.org/guidelines/

2 Venkat- Raman G, Tomson CR, Gao Y et al. New primary renal diagnosis codes for the ERA-EDTA. Nephrol Dial Transpl 2012; 27:44144419

3 http://www.renal.org/information-resources/the-uk-eckd-guide/aboutegfr\#sthash.K4QM6ZJB.dpbs

4 http://www.nomisweb.co.uk/census/2011/LC2101EW/view/ 2092957703?rows $=$ c_ethpuk11\&cols=c_age

$5 \mathrm{Kazmi} \mathrm{WH}$, et al. Late nephrology referral and mortality among patients with end-stage renal disease: a propensity score analysis. Nephrology Dialysis Transplantation 2004;19(7):1808-1814

6 Roubicek C, et al. Timing of nephrology referral: Influence on mortality and morbidity. American journal of kidney diseases: the official journal of the National Kidney Foundation 2000;36(1):35-41

7 Cochrane Database Syst Rev. Early referral to specialist nephrology services for preventing the progression to end-stage kidney disease. 2014 Jun 18;6:CD007333. doi: 10.1002/14651858.CD007333.pub2
8 Winkelmayer WC, et al. A Propensity Analysis of Late Versus Early Nephrologist Referral and Mortality on Dialysis. Journal of the American Society of Nephrology 2003;14(2):486-492

9 United States Renal Data System. 2017 USRDS annual data report: Epidemiology of kidney disease in the United States. National Institutes of Health, National Institute of Diabetes and Digestive and Kidney Diseases, Bethesda, MD, 2017

10 Caskey FJ, Jager KJ. A population approach to renal replacement therapy epidemiology: lessons from the EVEREST study. Nephrol Dial Transplant. 2014 Aug;29(8):1494-9. doi: 10.1093/ndt/gft390. Epub 2013 Oct 28

$11 \mathrm{https} / /$ www.nice.org.uk/guidance/cg182

12 Gallagher et al. A programme to spread eGFR graph surveillance for the early identification, support and treatment of people with progressive chronic kidney disease (ASSIST-CKD): protocol for the stepped wedge implementation and evaluation of an intervention to reduce late presentation for renal replacement therapy. BMC Nephrology (2017) 18:131 DOI 10.1186/s12882-017-0522-9 